\title{
La política de tierras para la población desplazada 2001-2011: de la protección a la restitución
}

\author{
Land policy for populations displaced in 2001-2011: \\ from protection to restitution \\ A política de terras para a população deslocada 2001-2011: \\ da proteção à restituição
}

\author{
MARÍA del Rosario EsTRAdA H. \\ Universidad del Rosario, Colombia \\ Nadia Margarita Rodríguez J. \\ Universidad del Rosario, Colombia
}

FECHA DE RECEPCIÓN: 22 de JULIO de 2013 • FECHA DE ACEPTACIÓN: 11 DE DICIEMBRE de 2013

Doi: dx.doi.org/10.12804/esj16.1.2014.02

Para citar este artículo: Estrada H., M. R. y Rodríguez J., N. M. (2014). La política de tierras para la población desplazada 20012011: de la protección a la restitución. Estudios Socio-Jurídicos, 16(1), pp. 75-121. doi: dx.doi.org/10.12804/esj16.1.2014.02

\section{RESUMEN}

El proceso político y jurídico que dio origen al capítulo sobre restitución de tierras de la Ley 1448, o Ley de Víctimas, ha tenido una trayectoria amplia y compleja, en la que se produce una evolución de gran magnitud puesto que se pasa de la idea original de protección a la de restitución. En el presente artículo nos proponemos tres objetivos: reconstruir la trayectoria institucional del Proyecto de Protección de Tierras y Patrimonio para la población desplazada, como un caso particular dentro de la institucionalidad y como gestor de la política de restitución de tierras; en segundo término, buscamos mostrar los avances técnicos que posibilitaron esa evolución desde la idea de protección hasta la de restitución y, finalmente, analizar las lógicas gubernamentales que orientaron este proceso. Todo lo anterior desde un marco conceptual de la sociología y antropología política, mostrando la interacción entre diferentes actores e intereses, con lógicas de gobierno que superan al Estado (este primer estudio se sustenta en los archivos y documentos producidos y publicados por el proyecto).

* Socióloga de la Universidad del Rosario. Joven investigadora de la Escuela de Ciencias Humanas de la misma Universidad. Correo electrónico: rosario.estrada89@gmail.com

** Doctora en Sociología de la Universidad de la Sorbona - París. Profesora de carrera del programa de Sociología, Escuela de Ciencias Humanas, Universidad del Rosario. Correo electrónico: nadia.rodriguez@urosario.edu.co 
Palabras claves: restitución de tierras, protección, gubernamentalidad, socioantropología política.

\section{ABSTRACT}

The political and legal process that concluded with the inclusion of a chapter on land restitution in law of 1448, known as the victims' law, has traveled a long and complex path, and has undergone a major shift, moving from the original idea of protection to restitution. In this paper we propose three objectives: to rebuild the institutional trajectory of the Bill for the Protection of Land and Property of the displaced population, as a particular case within the institutions that later gave rise to the restitution policy; second, to show the technical advances that made this evolution from the idea of protection to restitution possible; and lastly, we analyze the governmental logic that guided the process. All this is analyzed based on a conceptual framework of sociology and political anthropology, showing the interaction between different actors and interests, involving government dynamics that surpass the state (this first study is based on the files and documents produced and published by the project).

Key words: restitution of lands, protection, governmentalness, political socioanthropology.

\section{RESUMO}

O processo político e jurídico que deu origem ao capítulo sobre restituição de terras da lei 1448, ou lei de vítimas, tem tido uma trajetória ampla e complexa, na que se produz uma evolução de grande magnitude porquanto se passa da ideia original de proteção à de restituição. No presente artigo nos propomos três objetivos: reconstruir a trajetória institucional do Projeto de Proteção de Terras e Patrimônio para a população deslocada, como um caso particular dentro da institucionalidade e como gestor da política de restituição de terras; em segundo plano, buscamos mostrar os avances técnicos que possibilitaram essa evolução desde a ideia de proteção até a de restituição; e, finalmente, analisar as lógicas governamentais eu orientaram este processo. Todo o anterior desde um marco conceitual da sociologia e antropologia política, mostrando a interação entre diferentes atores e interesses, com lógicas de governo que superam ao Estado. Finalmente, este primeiro estudo sustenta-se nos arquivos e documentos produzidos e publicados pelo Projeto.

Palavras-Chave: restituição de terras, proteção, governamentalidade, sócioantropologia política. 


\section{Introducción}

La Ley 1448 de 2011, conocida como Ley de Víctimas, y el proceso de reparación que ella reglamenta, representan un hito histórico en Colombia, no solo por el reconocimiento del conflicto armado por parte del Estado colombiano, sino además, por ser un reto político, económico, jurídico y social. A partir de su sanción en junio del 2011, y desde la perspectiva de diferentes actores, la Ley ha desencadenado innumerables debates que han puesto en la escena pública tanto aplausos como críticas y mucho escepticismo frente a su cumplimiento. Además de los temas relacionados con el reconocimiento, la indemnización y reparación a las víctimas, la Ley, en su capítulo III, reglamenta la política de restitución de la tierra a la población despojada de manera violenta del año 91 en adelante. Es ahí donde se sitúa nuestra investigación, intentando rastrear desde 1997 el proceso político y jurídico que dio origen al capítulo III.

Nos interesa mostrar que la amplia trayectoria de la política de restitución de tierras va más allá de la Ley, pudiendo ser analizada a la luz de las lógicas gubernamentales que orientaron el proceso. Así, partiendo de un análisis documental, jurídico y testimonial, hemos llevado a cabo un examen socio jurídico de la evolución de los conceptos y de las instituciones a cargo. Como primer producto, presentaremos un análisis de los archivos y documentos producidos y publicados por el Proyecto de Protección de Tierras y Patrimonio para la Población Desplazada (en adelante PPTP), antecesor de la Unidad de Restitución de Tierras (en adelante URT). El artículo se acompaña del testimonio de funcionarios del PPTP, pero la etnografía que hemos realizado, por motivos de alcance, se divulgará en otras publicaciones.

En el presente documento analizaremos los avances producidos desde 2001, momento en el cual se crea el PPTP respondiendo al Decreto Reglamentario $2007^{1}$ (2001) de la Ley 387 de 1997. Intentaremos reconstruir

\footnotetext{
1 El Decreto reglamenta parcialmente los artículos 7, 17 y 19 de la Ley 387 de 1997, amplía las responsabilidades de los Comités de Atención Integral a la Población Desplazada ya creados con la Ley y les obliga a emitir declaraciones sobre los predios abandonados e identificar el tipo de ocupación del predio (propietarios, poseedores, tenedores y ocupantes). Y empieza a regular la articulación interinstitucional y las responsabilidades entre el Incoder, la Superintendencia de Notariado y Registro, el Catastro (en el Instituto geográfico Agustín Codazzi) y la Red de Solidaridad Social
} 
la trayectoria de la institución a través de sus avances y logros técnicos en materia de protección de tierras y analizaremos los cambios en las lógicas de gobierno que transformaron el objetivo de protección de los predios en la posibilidad de restituirlos. Esto es vital dado que originariamente el objetivo era la protección y es justo en el desarrollo gradual del trabajo técnico donde germina la transformación hacia la idea de restitución. Comprendida la importancia de este cambio, entenderemos por trayectoria no solo la historia del proyecto sino también tres aspectos más amplios: 1) los avances técnicos en la protección de tierras, 2) los procesos de aprendizaje y 3) las estrategias desarrolladas dentro del proyecto para incidir en la política.

Sobre los documentos haremos un análisis de contenido que a la vez fue nuestra guía para el trabajo etnográfico. Es de señalar, por último, que este estudio pretende también sistematizar la experiencia institucional del PPTP, que por su particularidad merece ser reconstruida.

El marco conceptual para el análisis contempla varias aproximaciones de la sociología política y del Estado, ya que el PPTP fue un programa de gobierno marcado por un proceso político que buscaba responder a unas formas determinadas de racionalidad de gobierno. En este sentido, entendemos lo político como parte de un "proceso público de toma de decisiones y de resolución de conflictos que incluye poderes diferenciados y fines determinados entre distintos grupos y actores" (Swartz, Turner y Tuden, 1966). Así, lo político ocurre en diferentes ámbitos, no solamente atañe al Estado, y allí confluyen complejas relaciones de poder.

El ejercicio del poder consiste en 'conducir conductas' [...] En el fondo, el poder es menos una confrontación entre dos adversarios o la vinculación de uno con otro, que una cuestión de gobierno. Se debe dar a esta palabra el amplio significado que poseía en el siglo XVI, 'gobierno' no se refería únicamente a las estructuras políticas o a la gestión de los Estados [...] No solo cubría las formas instituidas y legítimas de sujeción económica o política sino también de modos de acción, más o menos pensados y calculados, destinados a actuar sobre las posibilidades de acción de otros individuos. Gobernar, en este sentido, es estructurar el posible campo de acción de los otros (Foucault, 1988, p. 24).

(después Agencia Presidencial para la Acción Social) y la cooperación internacional para establecer una ruta de protección patrimonial. 
Para el caso que nos ocupa, las diferentes lógicas de gobierno que han orientado la política de protección y restitución de tierras se entienden como procesos políticos en los cuales han interferido múltiples actores. Para entender a ambos - procesos y actores- proponemos una aproximación etnográfica de una institución del Estado, y nos apoyamos en Trouillot (2001, 2011) quien refiere tres ideas fundamentales: 1) el Estado, más que un aparato, es un conjunto de procesos, 2) el poder del Estado no está 'fijado' solamente en las instituciones, es decir que las relaciones de poder que intervienen en las decisiones políticas que toma el Estado van más allá de las instituciones públicas, involucrando múltiples tipos de actores, y 3) este poder se enmarca en una esfera que desborda lo local y está fuertemente influenciado por escenarios e interacciones en el espacio político global.

Entendiendo lo político como un proceso, "El estudio de lo político es, entonces, el estudio de los procesos relacionados con la implementación y la determinación de fines públicos y el uso diferencial del poder por los miembros del grupo involucrado en tales fines" (Swartz et al., 1966, p. 107). A partir de estos planteamientos no podemos pensar el Estado como una unidad o aparato coherente unificado que nos "enfrenta y domina" (Haidar, 2005), sino como una serie de intercambios de poder particular que poseen una dinámica propia, que además se ve influida por el trabajo de los funcionarios o burócratas que van determinando los destinos de las formas de gobierno o de los mecanismos técnicos para definirlas.

Desde esta definición, el Estado -y los intereses de actores que él representa y los que lo conforman- tiene un papel importante en las prácticas, tanto políticas como económicas, y en las relaciones sociales (Trouillot, 2001, p. 127). Así, el Estado no es solo un aparato institucional sino un conjunto de prácticas y procesos gestados por un colectivo de burócratas que afectan a múltiples grupos de actores.

Por otro lado, Rose y Miller (1992) demostraron cómo el poder político se ejerce a través de "un número de alianzas cambiantes entre las autoridades de diversos proyectos para gobernar una multitud de facetas de la actividad económica, social y la conducta individual" (Rose y Miller, 1992, p. 174). Retomando la perspectiva foucaultiana para identificar las formas de gubernamentalidad del Estado, los autores proponen: 
Situados en esta perspectiva la cuestión no es considerar el gobierno en términos de "poder del Estado", sino dilucidar cómo, y en qué medida, el Estado es articulado en la actividad de gobierno: qué relaciones se establecen entre los políticos y otras actividades; qué fuentes, fuerzas, personas, saber o legitimidad son utilizados a través de qué dispositivos y técnicas se tornan operables esas diferentes tácticas (Rose y Miller, 1992, p. 177).

Esto significa que para estudiar el Estado y las técnicas de gobierno no basta con describir las estructuras, sino que resulta necesario entender las estrategias de los sujetos y las relaciones (de poder) entre ellos, que muchas veces determinan y sobrepasan al Estado. Dichas técnicas y la lógica gubernamental que las sustenta se desarrollan en contextos históricos determinados (Grinberg, 2007).

Finalmente, entender al Estado y las instituciones como procesos implica también pensar la escala en la que tienen lugar las interacciones entre actores e intereses. Siguiendo el planteamiento de Trouillot, las interrelaciones no se encuentran solo en una esfera, ya que la intervención estatal se enfrenta constantemente a las políticas 'globales', sino también, para el caso que estudiamos, a los poderes locales: "Los Estados cada vez sirven menos como contenedores ideológicos y culturales, hay nuevos procesos y prácticas que rechazan la forma típica estatal" (Trouillot, 2001, p. 132). Sobre este aspecto, es de resaltar que el PPTP tiene algunas particularidades: fue financiado en su totalidad por la cooperación internacional y, en este sentido, sus formas de funcionamiento respondieron en gran medida a otras lógicas que no eran exactamente las del gobierno que lo creó (PPTP, 2010, pp. 29, 37). Nos situamos así en un fragmento del Estado cuyo ejercicio está determinado por una agenda de cooperación internacional.

Para nuestra argumentación comenzaremos abordando las racionalidades políticas - referidas a los discursos políticos- que la institución (el PPTP en este caso) agencia para justificar sus acciones. En ellas está implícita una lógica de acción, pero también una conceptualización de los sujetos sobre los cuales se gobierna (Rose y Miller, 1992, p. 178). En segunda instancia, están los "programas de gobierno", que son las estrategias y dispositivos que se ponen en marcha para intervenir a partir de las racionalidades que serían lo "deseable". En este caso se trata de las estructuras que determinan hasta dónde es "posible" intervenir (Rose y Miller, 1992, p.182). Finalmente, 
las "tecnologías de gobierno" son el conjunto de procedimientos y técnicas que materializan y dirigen las acciones a través de las cuales se implementan las racionalidades y programas de gobierno (Miller y Rose, 1990, pp.1-30). Allí confluyen diversas fuerzas: jurídicas, profesionales, administrativas, financieras y judiciales.

Partiendo de estas tres dimensiones, explicaremos el proceso por el cual la idea original de la protección de bienes a la población desplazada, poco a poco, va abriendo el camino a la posibilidad de la restitución de la tierra. Recordemos, sin embargo, que por ahora solo abordaremos el análisis documental; más adelante nos centraremos en el corpus de datos testimoniales de los funcionarios que participaron y gestaron la política de restitución de tierras. Pero, antes de entrar en este análisis, conviene aportar algunos datos de contexto.

\section{Origen de la política de protección de tierras}

\section{a) Contextualización del fenómeno del desplazamiento forzado}

Como se mencionó en la introducción, la categoría jurídica de desplazado surge a partir de 1997 con la formulación de la Ley 387. En ella "se adoptan medidas para la prevención del desplazamiento forzado; la atención, protección, consolidación y estabilización socioeconómica de los desplazados por la violencia" (Ley 387 de 1997). Sin embargo, desde 1994 el tema se visibilizó "no solo con aportes de la academia al tema, también la producción de investigaciones de entidades públicas, de consultores, de organizaciones sociales y ONG" (Machado, 2004a, p. 40).

El fenómeno de desplazamiento por actos violentos, lejos de ser nuevo, ha sido constitutivo de la historia nacional (Tovar, 2001), pero es a partir de la década de los años 50 cuando se empiezan a masificar las migraciones forzosas a causa de la guerra y la violencia. Para Daniel Pécaut (2001) la época de La Violencia es el 'contexto inicial' en el que se sustenta la violencia posterior y también hace que se empiece a "normalizar", implicando, además de un enorme número de víctimas, la definición de una estructura agraria sustentada en las grandes haciendas y propiedades de las elites terratenientes. Es en este contexto en el que se va a mantener un conflicto 
continuo en el nivel local no solamente por la tierra sino por el control político. Colombia, a pesar de ser reconocida como una nación de tradición democrática, mantiene unas estructuras locales donde los alcaldes, notarios y jueces conservan un enorme poder partidista y clientelista sobre la propiedad (Gutiérrez, 2013). Fue bajo está lógica que a partir de los años 1970 estas elites locales y regionales alentaron el fortalecimiento de grupos paramilitares o ejércitos privados, "permitiéndoles actuar en red con toda clase de actores, tanto legales como ilegales" (Gutiérrez, 2012, p. 128).

Durante toda la segunda mitad del siglo XX, especialmente a partir de la década de los 70, dicha dinámica se ha mantenido y agudizado, fruto de la relación del Estado y el régimen político colombiano con el conflicto armado, el narcotráfico, la presión por la tierra para el desarrollo agro-industrial y el paramilitarismo (Gutiérrez, 2012, p. 104). Dichas alianzas son ejemplo de las manifestaciones de la ilegalidad bajo la que se ha construido la democracia colombiana a lo largo del siglo $\mathrm{XX}$, y causantes de un aumento de la violencia desde mediados de los 70. Pero, según cifras de Codhes, es indudable que el fenómeno se agudiza en las últimas décadas:

[...] en los últimos 25 años (1985-2010) por lo menos 5.195.620 personas (esto es, 1.039.124 hogares) han sido desplazadas a causa de la violencia. Esto significa que en promedio, cada año del último cuarto de siglo unas 208.000 personas padecieron desplazamiento forzado. Es decir, el $11,42 \%$ del total de la población colombiana (casi 12 de cada 100 colombianos) fue obligada a cambiar de lugar de residencia porque su vida, su integridad física o su libertad fueron vulneradas o seriamente amenazadas" (Codhes, 2011, p.24).

Estudios como los realizados por Ana María Ibáñez y Carlos Eduardo Vélez muestran una correlación "entre los incrementos de los homicidios políticos y el número de familias desplazadas" (Ibáñez y Vélez, 2003, p.2). Sin embargo, esta explicación sobre el conflicto armado como determinante del desplazamiento implica tener en cuenta factores de carácter estructural que influyen en esta situación (Pérez, 2004, p. 49). Así, en la búsqueda de respuestas, Bejarano, Echandía, Escobedo y León (1997), Sánchez (2007) y Machado (2009) han desvirtuado la hipótesis de que la pobreza sea la única causa estructural para la generación de conflicto y, por tanto, del desplazamiento. Por el contrario, Libardo Sarmiento (2000) y Martha Inés Villa 
(2006) sostienen que justamente en territorios donde hay mayor cantidad de riqueza (petróleo, cultivos ilícitos, minería, ganadería extensiva, etc.) es donde se encuentra una relación entre conflicto armado y desplazamiento (Sarmiento, 2000, p. 10).

Paola García (2011) asegura que el acaparamiento de las tierras en Colombia ha sido causado por la búsqueda de un proceso de desterritorialización a manos de los grupos armados, especialmente de los grupos paramilitares, con el objetivo de apropiarse de los recursos naturales. Por ejemplo, en la región del Bajo Atrato y en Tumaco la apropiación de la tierra en la década de 1990 tenía unos intereses específicos: "la expansión de los cultivos de palma africana y la puesta en marcha de grandes proyectos de infraestructura como un canal interoceánico y la extensión de la carretera panamericana" (García, 2011, p. 12).

Casos como los de Nariño y Chocó son solo dos ejemplos del modelo de desarrollo agroindustrial, "violatorio en lo legal y lesivo en lo social" (García, 2011, p. 14), que desde hace varias décadas está implementando Colombia. Las actuaciones de los empresarios de cultivos extensivos, palmeros en particular, y de los inversionistas privados para apropiarse y ejercer control sobre el territorio en la mayoría de los casos (Tumaco y el Bajo Atrato, por ejemplo), han estado auspiciados por el Estado colombiano, con el apoyo de las acciones violentas de los grupos paramilitares.

Tras las acciones de los grupos armados se camuflan múltiples intereses, de ahí que los más recientes estudios de los expertos en el tema afirmen que el desplazamiento y el despojo no son una consecuencia de la guerra, sino una estrategia sistemática de acaparamiento y de control territorial. Es decir, el desplazamiento no se genera a causa de la guerra, sino que hay guerra para que haya desplazados (Machado, 2004b). Estos hechos ocurren al margen o incluso a la sombra de aparatos políticos legítimos e ilegítimos. Autores como Gonzalo Sánchez y Ricardo Peñaranda (2007) y Ana María Ibáñez (Ibáñez y Vélez, 2003) han afirmado que la violencia en el país puede explicarse a partir de "la ilegitimidad, la pérdida de credibilidad, la ausencia y la debilidad del Estado" (Sánchez, 2007, p. 391). A ello se suman las economías ilícitas que han jugado un papel fundamental en el aumento del conflicto, en la degradación de las estrategias de control y la exacerbación del despojo y abandono; las cifras de Codhes demuestran que el desplazamiento y las zonas de cultivo ilícito están fuertemente relacionados (Codhes, 2011). 
Según estudios realizados por Ibáñez y Querubín (2004), las mayores causas del desplazamiento son la amenaza y el hostigamiento a la población por parte de los paramilitares (50\%), seguidas por la guerrilla (20\%). Adicionalmente, se debe señalar que los desplazamientos

[...] no siempre responden a acciones armadas específicas, sino que muchas veces la sola llegada de grupos insurgentes o paramilitares es un factor determinante para la huida de la población. Esto en el marco de las amenazas a las que se ve sometida la población ante supuestos o reales vínculos con alguno de los actores armados (Pérez, 2004, p. 52).

Las estrategias de 'expulsión' de la población son varias; así, para investigadores como Martha Inés Villa (2006) el despojo no es producto de una sola acción, sino del miedo y el hostigamiento reiterativos: "El desplazamiento, antes que un suceso intempestivo e inesperado, es el resultado de un proceso de exacerbación de un ambiente de terror, de miedos acumulados, de una ya larga historia de control de la población por parte de los grupos armados" (Castillejo, 2000, citado por Villa, 2006, p. 16). En todo caso, se trata de una estrategia que se aprovecha de la debilidad del Estado en materia de formalización de la propiedad rural y agraria para despojar a los pequeños productores que carecen de instrumento jurídico alguno para reclamar las propiedades.

Este es, grosso modo, el fenómeno al que se enfrentaba en su momento el proyecto de tierras, de ahí surgen sus cinco retos más relevantes: 1) desarrollar las técnicas para garantizar la protección -con el agravante de la inexistencia de sistemas de información-; 2) la magnitud del fenómeno, en términos geográficos y de número de personas -así como su agravamiento-, pues en 2001 se multiplicaba con el fortalecimiento de los grupos paramilitares; 3 ) el poco interés de poderes locales y nacionales por avanzar en el proceso, ya que muchas de estas instancias de gobierno estaban cooptadas por los mismos poderes que generaban el despojo; 4) la dispersión y vulnerabilidad de la población desplazada que seguía en condición de amenaza, todo lo cual hacía difícil su identificación y la solicitud de protección de tierras; y 5) una incertidumbre total sobre la utilidad y el futuro que tendría la protección de las tierras. 
El Decreto Reglamentario 2007 de 2001 de la Ley 387 de 1997 empieza a crear los mecanismos necesarios para hacer posible la protección del patrimonio de la población desplazada. Surge fruto de dos experiencias de trabajo con comunidad desplazada realizadas por funcionarios de la Red de Solidaridad Social, ${ }^{2}$ quienes hicieron visible la magnitud y la gravedad del hecho, así como de la imperiosa urgencia de desarrollar herramientas técnicas e instrumentos jurídicos para la protección de la tierra. Cabe mencionar que quien lideró este equipo ocupó posteriormente la gerencia del PPTP durante diez años. El dato es de gran trascendencia toda vez que evidencia cómo, a través de personas, se empiezan a crear normas y conceptos que poco a poco se van consolidando en técnicas de gobierno.

El nacimiento del PPTP nos muestra la forma en que lo político incorpora múltiples intereses y fuerzas de poder. En concreto: jurídico, representado por la Corte Constitucional; administrativo, desde las iniciativas de los funcionarios; y geopolítico, con la intervención de la cooperación internacional. Se debe destacar que el aparato jurídico y normativo contribuyó en decisiones políticas que no dependían de las instituciones y que sobrepasaban la voluntad gubernamental. ${ }^{3}$

El Decreto 2007 establecía la articulación de las instituciones encargadas del registro de propiedad para hacer posible su protección, pero la tarea resultaba titánica tanto por el atraso en el registro y la ausencia de información como por la inexistencia de mecanismos y de una cultura de intercambio interinstitucional. Ciertamente, las instituciones llamadas a colaborar tenían potestades sobre la tenencia de la tierra, pero cada una

2 Según el testimonio de una funcionaria, los antecedentes del proyecto se sitúan antes del Decreto en una investigación de la Red de Solidaridad Social en 1999, financiada por ACNUR, sobre el acaparamiento de tierras y el desplazamiento forzado. Algunos participantes en esa investigación empezaron a trabajar en la reglamentación de la Ley 387 que hasta entonces existía solo en el papel. Específicamente el artículo 19 planteaba la necesidad de crear un registro de tierras despojadas, sin embargo, desde la consolidación de la ley era un tema que se había pasado por alto.

3 Por ejemplo, la Corte Constitucional y la cooperación internacional "posicionaron" en la agenda pública la aplicación del artículo 19 de la Ley 387 con el Decreto Reglamentario 2007, la Sentencia T-268 de 2003, la Sentencia T-025 de 2004 y, en particular, sus Autos de seguimiento, en especial el auto 008 de 2009, la Sentencia C-370 de 2006, la Ley 1152 de 2007, la Ley 1182 de 2008, el borrador de la Ley de Víctimas que nunca llega al Congreso y, finalmente, la Ley 1448 de 2011 son el cuerpo normativo desde donde se identificaban las herramientas que podrían ser aplicadas para la construcción de las rutas de protección. 
había sido creada con objetivos, contextos y lógicas de ejecución de sus mandatos muy diferentes y nunca pensadas para complementarse las unas a las otras. Veamos este panorama institucional:

En primer lugar estaba el Incora (ahora Incoder), a la que el decreto señalaba como entidad responsable de gestionar el sistema de información que posibilitaba la protección (Registro Único de Protección de Tierras Abandonadas, en adelante RUPTA). La institución también debía titular los baldíos desde 1994 - tarea nunca llevada a cabo de forma transparente, desde sus inicios hasta hoy-. La entidad fue reestructurada en el año 2002, manteniendo dinámicas de corrupción y favoreciendo la acumulación, especialmente a nivel regional.

La Superintendencia de Notariado y Registro es el ente encargado del registro de transacciones y la validación de los títulos. Al igual que el Incoder, no tenía, ni tiene hoy día, instrumentos para el control regional del registro ni de los notarios que hacen parte importante de la estructura de poder local y que responden a dinámicas de clientelismo político. El papel de los notarios fue clave en la configuración del despojo, pues sin cotejo alguno escrituraron predios que no habían sido formalizados por campesinos propietarios, tenedores u ocupantes.

El Instituto Geográfico Agustín Codazzi, encargado del catastro, presentaba innumerables dificultades técnicas y presupuestales, así como un sistema de información catastral desactualizado.

La Red de Solidaridad Social, convertida en 2002, bajo el gobierno Uribe, en la Agencia Presidencial para la Acción Social, tenía múltiples tareas, entre ellas dar cumplimiento a las medidas y programas de atención a la población desplazada y coordinar la cooperación internacional. Y precisamente esta última, la cooperación internacional, en especial desde la Unidad Técnica Conjunta, se encargaba de financiar un abanico de proyectos destinados a los problemas más acuciantes en derechos humanos-como la migración interna, fruto no solo del conflicto armado, sino del uso del desplazamiento y el despojo como estrategia para la concentración de la tierra-.

Con semejante panorama de instituciones corruptas, limitadas, sin sistemas de información y recelosas de sus funciones, no es difícil entender que la colaboración era impensable y mucho más la protección y registro de las tierras. A ello se sumaban la problemática de la informalidad de la 
tierra, que impedía la identificación de los predios, y la dispersión cada vez mayor de la población desplazada. Otro hecho vino a sumarse a la reglamentación para avanzar en el proceso, lo que muestra que a veces varias fuerzas mueven las dinámicas políticas: gracias a una propuesta presentada al Banco Mundial se obtiene la financiación para el proyecto. ${ }^{4}$ Diríamos, en resumen, que prácticamente al centralizar toda la política referente a la población desplazada en Acción Social, la gestión de los recursos era competencia de la cooperación internacional, por lo cual es allí donde nace el proyecto.

Este origen marca las características del proyecto en su forma primigenia: 1) dirección con una línea extremadamente técnica, 2) reducido personal de jóvenes ingenieros catastrales, 3) operación cobijada bajo el paraguas de Acción Social, 4) con una misión muy clara de implementar lo estipulado en el Decreto 2007 sobre protección y 5) con una sólida financiación del Banco Mundial que le permitió mantener una estructura más parecida a la de una ONG que a la de una institución del Estado.

De ese contexto derivan ciertas particularidades que conviene señalar: por una parte, se mantuvo cierta independencia frente a las lógicas de Acción Social. En palabras de una funcionaria "esto nos permitió hablar ciertos temas que, más que coyunturales, resultaban estructurales y muy políticos" (entrevista 2, funcionaria del PPTP y ahora de la URT, 14 de noviembre de 2012). En segundo lugar, la rendición de cuentas y el grado de avance, en la mayoría de los casos, se llevaban a cabo no frente al Estado, sino frente a la cooperación internacional, lo que mantuvo en todo momento una mayor capacidad de injerencia en los avances técnicos de la que tenía el propio gobierno. Según otro funcionario: "Nosotros vimos una estrategia muy importante con los cooperantes: es que, cada vez que nosotros encontrábamos cosas que por ser gobierno y estar bajo la cobija de Acción Social, no podíamos decir, pero sí podían los cooperantes" (entrevista 4, 9 de abril de 2013, funcionaria del PPTP, transcrita por Sebastián Valbuena). Se generó pues una estrategia basada en manejar cautelosamente la información, dejando que fuera la cooperación internacional quien presentara los temas críticos, para poder ellos seguir trabajando en la problemática.

4 La propuesta es presentada por algunas de las personas que participaron en la reglamentación. Sin esta financiación externa el gobierno colombiano nunca habría empezado a trabajar sobre la protección de los predios. 
Dinámica que se vio favorecida por el perfil técnico de los informes: "En cierta medida éramos Acción Social, pero nos movíamos con otra lógica, no con la lógica del eje general del presupuesto" (entrevista 1, 29 de mayo de 2013, funcionaria de la URT que trabajó en el PPTP. Transcrita por Rosario Estrada); en tercer lugar, la contratación de personal se hacía igualmente bajo los términos del financiador y no del Estado, de tal forma que quienes se vincularon lo hicieron como contratistas y nunca se consideraron funcionarios públicos. Este mismo modus operandi amparó tanto los procesos de selección como los baremos de remuneración, resultando en la incorporación de un equipo comprometido y de alto nivel profesional. Finalmente, otra característica determinante fue que en sus diez años de existencia, antes de convertirse en Unidad de Restitución de Tierras, funcionó en un contexto político, nacional y local, adverso al establecimiento de una política contundente de protección de la tierra, lo que da cuenta de que las lógicas de gobierno no son homogéneas y que muchas veces el devenir de una institución o de una normativa depende de estrategias mucho más personales. No es difícil percibir que la gerencia, para cumplir sus objetivos, debió lidiar con las diferentes lógicas y presiones.

Vemos así cómo en el proyecto se superponen diferentes objetivos y formas de gubernamentalidad: 1) la obligación de mostrar resultados positivos frente a la Corte Constitucional, que hacía seguimiento a ley a través de varias sentencias a favor de la protección de los desplazados, ${ }^{5}$ 2) la respuesta a la cooperación internacional, que evaluaba los avances de acuerdo a los recursos invertidos, 3) el paso por la cooperación internacional para poder decir aquello que como gobierno era inadmisible, 4) la lógica interna de los consultores, comprometidos con el desarrollo de

5 La Corte Interamericana de Derechos y la Corte Constitucional colombiana se pronunciaron sobre el tema, algunos ejemplos son las medidas provisionales tomadas el 6 de marzo de 2003 (y posteriormente a través de las resoluciones del 17 de noviembre de 2004, del 15 de marzo de 2005, del 7 de febrero de 2006 y del 5 de febrero de 2008) para las comunidades asentadas en las cuencas de Jiguamiandó y Curvaradó, sobre las cuales la Corte Interamericana de Derechos Humanos le ordena al Estado colombiano que tome decisiones a favor de esta población. Uno de los pronunciamientos más importantes de la Corte Constitucional es la Sentencia T-025 de 2004, que se origina a partir de un cúmulo de tutelas presentadas por población desplazada que no había recibido atención por parte del gobierno. Declara un Estado de cosas inconstitucional dada la vulneración múltiple, masiva y continua de los derechos fundamentales de las personas desplazadas a causa de la violencia. La Corte igualmente ha expedido una serie de Autos que hacen seguimiento y dictan nuevas órdenes, como los Autos 092 de 2008, 004 de 2009, 005 de 2009, para proteger los derechos de las minorías étnicas victimas del desplazamiento forzado. 
herramientas para materializar la protección, 5) un contexto social y político adverso, en el que fenómeno se multiplicaba de manera exponencial ante los ojos del gobierno nacional y 6) la muestra de resultados manteniendo un bajo perfil frente a un gobierno adverso a desarrollar una política sólida en esta materia.

Así, entre 2003 y 2010 el proyecto va a producir un acervo documental importante que no solo sirvió como testimonio de los avances sino también como producto y requerimiento de la financiación que recibía de la cooperación internacional. Esta es otra particularidad del PPTP con respecto a otras instituciones públicas, donde las sistematizaciones de experiencias prácticamente no existen. Gran parte de lo que el proyecto hizo, su metodología y resultados, se encuentra documentado, facilitando la reconstrucción y análisis de la trayectoria institucional. Si bien se produjeron cerca de cuarenta publicaciones (entre cartillas informativas, informes de gestión y de investigación, y libros de recopilación y sistematización de las experiencias), no es menos cierto que algunos aspectos no quedaron registrados, en particular el desarrollo de una visión más crítica y una evaluación de resultados frente a la complejidad de la tarea. Partiendo de ese material reconstruiremos a continuación la trayectoria de la institución, dando cuenta de los cruces entre las diferentes lógicas señaladas anteriormente.

\section{Reconstrucción de la trayectoria institucional del PPTP}

\section{a) Primera fase (2002-2005): El diseño de las herramientas técnicas para la protección}

Con el objetivo de aportar las herramientas necesarias para dar cumplimiento a lo dispuesto en la normativa, ${ }^{6}$ el PPTP inició la primera etapa de la intervención entre 2002 y 2005 . En ella se desarrollan cuatro pasos: diseño de metodologías y herramientas, validación de las herramientas mediante la aplicación de pruebas piloto en cinco regiones del país, retroalimentación, ajuste y publicación de los manuales de procedimiento para la aplicación

6 Documentos jurídicos anteriores a 2003, a saber: la Sentencia SU 1150 de 2000, la Ley 387, el Decreto 2007 de 2001, la Sentencia T 327 de 2001, la Sentencia T 268 de 2003. 
y creación de la red interinstitucional de protección. Esta fase se puso en marcha en el año 2003, partiendo de la caracterización de un conjunto de variables críticas, a saber: la magnitud y dinámica del desplazamiento forzado, la distribución y usos de las tierras, la informalidad en la tenencia y la información y administración de tierras rurales.

En el libro La protección de tierras y territorios para la salvaguarda de los derechos patrimoniales de las víctimas (2010b) se señalan los principales logros de la fase I: a) diseño de metodologías y herramientas para la recolección de la información validadas institucional y comunitariamente, b) reconocimiento y apropiación del tema por parte de algunas de las instituciones, c) participación de líderes comunitarios en la validación de los productos del proyecto, d) producción de una caja de herramientas para la protección de los derechos sobre la tierra, e) manual de procedimiento para la aplicación de las rutas colectiva e individual de protección, f) incorporación de la protección patrimonial en el nuevo Plan Nacional de Atención a la Población Desplazada, g) estrategias para caracterizar los tipos de afectación de los territorios colectivos, h) estudios relacionados con la salvaguarda del patrimonio de las comunidades, i) diseño del Registro Único de Predios Abandonados $^{7}$ (Acción Social, 2010b, p. 9).

Metodológicamente se crean tres rutas para la protección que permanecerán vigentes por varios años: la ruta individual, la ruta colectiva y la ruta étnica (tabla 1).

En la ruta individual, la solicitud se hace ante el Ministerio Público o bien los catastros descentralizados individualizan física y jurídicamente el predio a proteger. El diseño metodológico siempre se pensó para la identificación real y material de los predios, aspecto que ninguna otra institución estaba lista para desarrollar; sin embargo, las limitaciones a este punto eran, ayer como hoy, los problemas de acceso y de seguridad.

La ruta colectiva opera cuando existe riesgo de desplazamiento, y estaba a cargo de los Comités Territoriales de Atención Integral a la Población Desplazada (CTAIPD) mediante una caracterización de la calidad legal de los predios y el tiempo de ocupación de los mismos.

La ruta étnica salvaguarda los derechos territoriales de los pueblos indígenas y las comunidades negras vulneradas, o en riesgo de serlo, a causa de

7 Como se dijo anteriormente, esto le correspondía al Incoder. 
la violencia o de mega-proyectos económicos. ${ }^{8}$ En esta vía, la comunidad es la encargada de pronunciarse y el Estado el de proteger la propiedad colectiva.

Tabla 1. Rutas de atención para la protección patrimonial para población desplazada

\begin{tabular}{|l|l|}
\hline \multicolumn{1}{|c|}{ Pasos ruta colectiva y étnica } & \multicolumn{1}{c|}{ Pasos ruta individual } \\
\hline $\begin{array}{l}\text { 1. Los CTAIPD emiten declarato- } \\
\text { ria de inminencia de riesgo de } \\
\text { desplazamiento, de desplaza- } \\
\text { miento forzado o mixta. }\end{array}$ & $\begin{array}{l}\text { 1. Presentar una solicitud ante el Ministerio Público. } \\
\text { 2. La solicitud es enviada a la Subgerencia de Tierras Rurales } \\
\text { del Incoder. }\end{array}$ \\
$\begin{array}{l}\text { 2. Ingreso al RUPTA. } \\
\begin{array}{l}\text { Los CTAIPD elaboran informe } \\
\text { de derechos sobre predios y } \\
\text { territorios que caracteriza la } \\
\text { relación con el predio. }\end{array}\end{array}$ & $\begin{array}{l}\text { 4. El Incoder individualiza física y jurídicamente el predio. } \\
\text { 5emite a la Oficina de Registros de Instrumentos Públicos } \\
\text { anotando la medida de protección en el folio de matrícula } \\
\text { inmobiliaria. }\end{array}$ \\
\hline
\end{tabular}

Fuente: Acción Social-PPTP, 2005e. ${ }^{9}$

En la Tabla 2 se evidencian los resultados de la aplicación de las medidas de protección durante el periodo 2002 a 2010, ${ }^{10}$ etapa en la que se ampararon 147.955 derechos sobre predios y territorios de población en riesgo o en situación de desplazamiento. La ruta individual cobijó el 26,47\% de los derechos, mientras que el 73,25\% restante se protegió mediante la implementación de la ruta colectiva. Este último fue el mecanismo más eficaz porque buscaba proteger veredas enteras, lo que a su vez permitía que la zona en su totalidad fuera protegida, sin importar la titulación -y no solamente un predio para el cual la localización geográfica, sin título de propiedad, se hacía mucho más difícil-. En conjunto, para el 30 de noviembre de 2010 el PPTP cubrió 4'741.940,39 hectáreas que contienen 119.854 predios, sobre los cuales 111.324 personas tienen o han ejercido derechos (Acción Social-PPTP, 2010b, p. 32)

8 De acuerdo con lo establecido en el Auto 005 de 2009.

9 "El procedimiento para elaborar estos informes contempla: i) acopio y cruce de la información suministrada por las instituciones, ii) recolección de información comunitaria de la zona, iii) cruce de la información institucional y comunitaria, iv) consolidación del informe, socializado con instituciones y comunidad, v) aval del Informe de Derechos sobre Predios y Territorios por parte del Comité y notificación a las comunidades e instituciones con competencias en la protección patrimonial" (Acción Social, 2011, p. 21).

10 Tomamos las cifras de 2010 para mostrar los logros en conjunto y la eficacia de las herramientas diseñadas en esta fase. También porque el proyecto empieza a publicar sus resultados a partir de esta fecha. 
Tabla 2. Aplicación de medidas de protección 2003-2010

\begin{tabular}{|l|l|l|l|l|}
\hline Rutas de protección & \multicolumn{5}{|c|}{ Variables } \\
\hline & Derechos & Personas & Predios & Área $^{14}$ (Has) \\
\hline COLECTIVA & 108.791 & 78.016 & 81.506 & $2.549 .385,82$ \\
\hline INDIVIDUAL & 39.164 & 33.308 & 38.348 & $2.192 .554,58$ \\
\hline Total & 147.955 & 111.324 & 119.854 & $4.741 .940,39$ \\
\hline
\end{tabular}

Datos CTAIPD y RUPTA, corte 30 de noviembre de 2010.

Fuente: Acción Social-PPTP, 2010b, p. 31.

En esta etapa se introdujo el enfoque diferencial para las mujeres, la niñez y la adolescencia. Para las mujeres, se detectó la situación de vulnerabilidad ligada a prácticas socio-culturales patriarcales que "las mantienen marginadas del conocimiento y decisiones sobre activos productivos como la tierra" (Acción Social, 2010b, p. 32). En cuanto a la participación por género, según calidad jurídica y ruta de protección, en la siguiente gráfica se observa cómo al interior de la ruta colectiva hay mayor participación de las mujeres propietarias, mientras que en la ruta individual predominan mujeres poseedoras. En cualquier caso, merece señalarse la evidencia de mejores niveles de protección para los hombres con respecto a las mujeres en las otras calidades jurídicas.

En el caso de la niñez y la adolescencia:

En situación de muerte de ambos padres, su condición de minoría de edad y su imposibilidad jurídica de contraer obligaciones y de disponer de sus bienes y patrimonio, se hacen fácilmente susceptibles al despojo, dado que no hay quien pueda velar por los bienes abandonados sobre los que tienen derechos como herederos (Acción Social, 2010b, pp. 19, 20).

Ante estas situaciones, el PPTP hace el ejercicio de hacer visibles los derechos patrimoniales de estas poblaciones.

Si nos referimos a los alcances de las medidas de protección patrimonial, el PPTP desarrolló acciones metodológicas para salvaguardar diferentes tipos de vínculos sobre las tierras (poseedores, ocupantes y tenedores ${ }^{11}$ ), no limi-

11 Ocupantes: Personas que tienen un contrato y se benefician económicamente de un inmueble, pero reconocen a otro como dueño o con un derecho mayor sobre la propiedad. Poseedores 
Gráfica 1. Personas naturales con derechos cobijados y relación jurídica y género.

Rutas individual y colectiva, 2003-2010

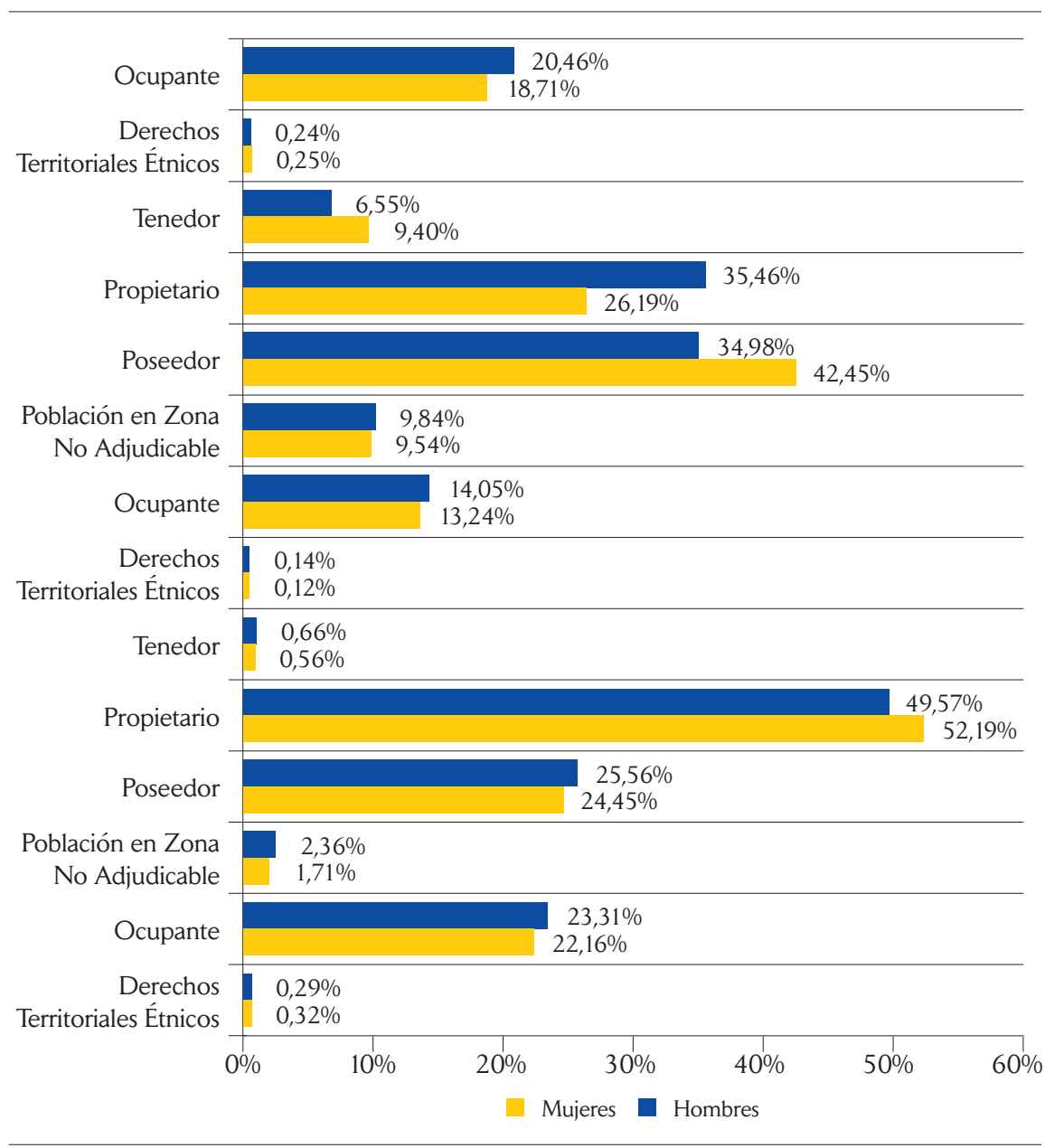

Datos CTAIPD y RUPTA, corte 30 de noviembre de 2010.

Fuente: Acción Social-PPTP, 2010.

tándose tan solo a proteger la propiedad legal de los predios - previniendo transacciones sin la autorización de los propietarios-, sino buscando además hacer públicos los otros vínculos que se han venido ejerciendo sobre la tierra, para poder también legalizar la propiedad. Como medida proba-

de buena y de mala fe: personas que habitan y explotan un terreno baldío, sin dueño aparente o conocido. Tenedores: personas que usan un inmueble de propiedad privada y no reconocen a otros como dueños. 
toria, la información relativa a la aplicación de la protección de derechos y vínculos con la tierra y los territorios está contenida en el RUPTA, a fin de dejar constancia de su existencia (Acción Social, 2010a). Este es un desarrollo importante porque, si bien la misión del proyecto era la protección, muy rápidamente se da cuenta de que el problema es la formalización; de ahí que empiece a orientar gran parte de sus esfuerzos en este sentido, con poco éxito por cierto, pues no contaba en ese momento con herramientas jurídicas y logísticas suficientes para adelantar la formalización.

Entre las principales utilidades de aplicar las medidas de protección, así como del RUPTA, se encuentra la de garantizar un medio probatorio para aportar en procesos policivos, penales, judiciales o administrativos, con fines de formalización: "este registro es un instrumento para exigir el reconocimiento de la ocupación sobre predios baldíos de la nación y con ello, la acumulación del periodo de ocupación material y el tiempo de abandono, a fin de acceder al procedimiento administrativo de titulación de baldíos" (Decreto 2007 de 2001, art. 7). Es cierto que nadie hablaba entonces de restituir los predios, pero ya los funcionarios empezaban a pensar que el registro debía servir algún día para devolver las tierras:

La veíamos muy remota [la idea de devolver], de hecho, en varias ocasiones pensamos que, en la medida en que iban aumentando el número de tierras y el número de casos, decíamos, bueno, tal vez si no hay mucho interés en el tema, podemos guardar una copia y, bueno, la llevamos al extranjero [...] Decíamos, bueno, esto tiene un sentido en el tema que sepan que esto ocurrió, que esto, aunque sea, sirva para verdad histórica y que algún momento puedan ser cogidos estos registros para devolverle la tierra a las personas (entrevista 1, realizada a una funcionaria del PPTP).

[...] pero proteger tierras y pensar que las iban a devolver, nunca. Pues la visión nuestra yo creo que era: protejamos, que después llegará la restitución. Sí, sabíamos que iba a servir para algo. Mmm, eso lo hicimos ahí pensando que en algún momento llegaría la restitución, pero nunca pensamos que fuera tan pronto. Además, un poco mirando lo que había ocurrido en otros países donde nunca era inmediato" (entrevista 3, realizada a un funcionario del PPTP que actualmente trabaja en la URT).

Así, la devolución germinaba en la cabeza de los funcionarios, pero nunca fue parte de la finalidad de la política de atención a la población 
desplazada, que solo llegaba a la protección, como lo especificaba el artículo 19 de la Ley 387. Si bien el Decreto 2007 mostraba el camino, la operacionalización de instrumentos técnicos partió de cero.

[...] no había claridad de cómo hacerlo, ni cuáles eran las competencias institucionales para materializar y operativizar eso que estaba definiendo la ley y, en alguna medida, el decreto. Incluso los alcances del decreto en su momento [tampoco] se entendía muy bien realmente cuáles eran los alcances. Y sobre todo, las instituciones sentían que no era un tema muy obligado, no era un tema muy conocido, no estaba claramente como prioritario en la agenda pública. Las entidades, cada una con sus propias, digamos, funciones y cargas misionales, y este es un tema más bien accesorio, [...] lo que se evidencia a través de este proyecto del Banco Mundial es que se necesita como un grupo dinamizador que se siente exclusivamente a pensar y a diseñar las metodologías, instrumentos y hacer la gestión necesaria para, primero, definir cómo hay que hacerlo, definirlo desde las realidades institucionales; divulgarlo, darlo a conocer y apoyar e impulsar la aplicación del mismo. Esto desde el enfoque institucional, que se llamó incluso "componente de desarrollo institucional" (entrevista 2, funcionaria del PPTP y ahora de la URT, 14 de noviembre de 2012).

En el caso de los poseedores, su aplicación permite que no se interrumpa el término de prescripción sobre los inmuebles abandonados, en el de los ocupantes acceder a los programas con el Incoder y para los tenedores es un medio de tener prelación en los procesos de acceso a tierra. Muchas de estas medidas, y las figuras técnicas y jurídicas creadas para este fin, se verán reflejadas en el capítulo tercero sobre la restitución de tierras de la Ley 1448, resaltando el proceso de aprendizaje que se produjo en el proyecto de tierras. Otro aspecto a señalar de la primera fase es que los avances técnicos fueron cotejados en trabajos de campo en cinco pilotos, lo que favoreció su perfeccionamiento y acople a contextos puntuales.

Por tanto, queremos destacar que, si bien el mandato del proyecto era garantizar la protección, desde hace diez años se está gestando ya el concepto de restitución, fruto de agendas gubernamentales diferentes a las del gobierno nacional. Así, aunque las instituciones están permeadas por lógicas de gobierno, no son las únicas fuerzas que construyen lo político, como lo afirman Rose y Miller. 


\section{b) Segunda fase (2005-2008): la protección se empieza aplicar en las regiones}

Entre 2005 y 2008 se definieron cinco líneas de trabajo: aplicación de las medidas de protección, transferencia de herramientas, sistemas de información, desarrollo de medidas complementarias y la Unidad de Gerencia. Estos componentes orientaron el quehacer de nueve equipos en las regiones y un equipo en el orden nacional.

Con respecto a las medidas de protección y actividades de transferencia, se logró un avance importante dando cobertura a 755 municipios, haciendo visibles los derechos informales sobre la tierra y dando a conocer su relación con una eventual restitución (Acción Social, 2005e, p. 14). El proceso exigió la preparación de condiciones institucionales y comunitarias a nivel local que ayudaran en la aplicación de cinco medidas: a) ampliación de las jornadas de protección, ${ }^{12}$ b) realización de campañas de divulgación masiva, c) utilización de medios alternativos de comunicación en el ámbito territorial, d) focalización de grupos de población en los cuales la protección tuviera mayor incidencia y e) impulso para conformar las mesas de tierras y los comités técnicos interinstitucionales - ya que la primera fase había mostrado que los CTAIPD no estaban funcionando en todas partes-. Se incorporaron nuevos departamentos: Antioquia, Caribe (Atlántico, Bolívar, Córdoba, Magdalena y Sucre), Chocó, Centro (Bogotá, Cundinamarca, Meta), Magdalena Medio, Nariño, Norte de Santander, Arauca, Tolima, Huila, Valle, Cauca (Acción Social, 2010b). Los resultados que arrojó la evaluación de esta segunda fase, según el PPTP, muestran que la intervención logró "la protección de 106.398 derechos de 76.844 personas, relacionadas con 83.450 predios, con una extensión estimada de 2.525 .565 hectáreas, las cuales se localizan en 755 municipios del país" (Acción Social, 2010b).

En esta fase se empieza a conformar un sistema de información en coordinación con el Incoder, que más adelante se convierte en el RUPTA, el cual incorporó además un software para que las Oficinas Regionales de Inscripción de Predios sistematizaran su información sobre índices de predios y propietarios, y se estructuró el Sistema de Monitoreo y Evaluación (SIME), herramienta que facilitó la organización de la información recolectada en

12 Jornadas en las que se atendían solicitudes de protección directamente en los municipios. 
terreno en tiempo real y administrar los planes de acción, tanto en las metas y resultados como en la ejecución de los recursos y presupuestos. Gran parte de la riqueza de la información que tiene sistematizada el proyecto se debe a esta herramienta, cuya existencia se explica por la relación del proyecto con la cooperación internacional, donde estos instrumentos son requeridos para mantener la financiación.

Es en esta fase cuando se empiezan a identificar claramente los que serían los principales obstáculos para la materialización efectiva de la devolución de predios:

[...] la falta de recursos judiciales eficaces para deshacer las negociaciones mediante las cuales se consolidan los actos de despojo; el repoblamiento de las tierras abandonadas o despojadas por personas puestas allí por los victimarios o por terceros de buena fe; ${ }^{13}$ la destrucción de los registros de propiedad o la ausencia de ellos en contextos con altos niveles de informalidad en la tenencia de la tierra:; ${ }^{14}$ la magnitud de las acciones de despojo, la diversidad de mecanismos, y la manera como algunos de los delitos o conductas fraudulentas se revisten de una "aparente legalidad" (Acción Social, 2010).

Parte de la estrategia del proyecto fue trabajar en el fortalecimiento de la capacidad institucional de las entidades participantes en las medidas de protección. Como punto de partida se estableció un diagnóstico que permitió establecer cuatro ejes desde los que se daría apoyo a las instituciones: a) soporte en el diseño de procedimientos, b) transferencia de procedimientos, herramientas e instrumentos para la generación de capacidades, c) apoyo logístico y d) seguimiento. Estas actividades generaron múltiples fricciones y cuestionamientos sobre el rol del proyecto, lo cual explica que, en materia de coordinación, no se lograra gran parte de sus propuestas. La Superintendencia de Notariado, por ejemplo, cambió de dirección en varias

13 Frente al repoblamiento de los predios por parte de terceros, el PPTP sugiere que deben reconocerse los derechos de los ocupantes primarios, aun cuando los nuevos pobladores sean de buena fe.

14 Con respecto a la pérdida o alteración de los documentos que certifican la propiedad, el PPTP sugiere que deben ser aceptados diversos medios probatorios para acreditar la titularidad de los derechos, así como establecer diferentes presunciones, reconociendo que la carga de la prueba no debe recaer sobre la víctima. 
ocasiones durante el periodo, siendo algunos subdirectores más reticentes que otros. Por el contrario, el IGAC siempre contó con mucha disposición para la articulación interinstitucional. El Incoder, por su parte, fruto de su reestructuración, mantuvo un proceso mucho más lento y desigual según los periodos.

Los documentos de sistematización de la experiencia, publicados por el PPTP, dejan claro que en todas las entidades con competencias se crearon las directrices para la comprensión y aplicación de las rutas de protección, con lo que esperaban que se diera una respuesta ágil y oportuna no solo a los procedimientos de protección sino también a los cambios normativos. Sin embargo, el proyecto nunca hizo un análisis crítico que dé cuenta de la efectividad de estos procedimientos. De nuevo advertimos que al delegar la sistematización de la experiencia en los mismos funcionarios que trabajaron en el PPTP, se perdió objetividad en el análisis del impacto que tuvieron las intervenciones institucionales del proyecto.

\section{c) Tercera fase (2008-2012): fase de transición hacia la restitución}

La tercera fase estaba presupuestada para ejecutarse entre 2008 y 2012, periodo en el que se da un vuelco total al proyecto con el cambio de gobierno y cuando la Ley de Víctimas se convierte en bandera del presidente Juan Manuel Santos. Esto tendrá una incidencia relevante al tomar la decisión política de transformar el proyecto en Unidad Administrativa Especial de Gestión y Restitución de Tierras. En esta etapa se fortaleció la estructura del Comité Técnico Interinstitucional de Protección, se trabajaron los instrumentos para la identificación de las personas y los predios, y se inició la recolección de pruebas que soportan la relación jurídica con los predios, información que era registrada en el RUPTA, sirviendo como archivo. Una vez que el RUPTA es retomado por el Incoder el proceso se estanca parcialmente. Ya para entonces se empezaba a hablar de retornos y en algunas regiones había intentos importantes de recuperación territorial. Para Acción Social la base de datos se convirtió en un instrumento fundamental para facilitar esta tarea (Acción Social, 2010c, pp. 15-16). La sociedad civil también estaba haciendo avances de magnitud al organizarse y, acompañada de algunas ONG y de la cooperación internacional, empezaba a desarrollar procesos de retorno, como el de Las Pavas en 2009 (de donde nuevamente 
son expulsados los campesinos para realizar un nuevo retorno en 2011), o los casos de Curbaradó y Jiguamiandó que se convierten en casos emblemáticos de intentos de recuperación de la tierra. A este escenario se suma la visibilización de las masacres más importantes como son la de Trujillo y El Salado y las confesiones de los paramilitares que develaron sus alianzas con militares, actores económicos y políticos. ${ }^{15}$

En lo referido a la protección de las tierras, en 2009, a raíz de las transformaciones normativas e institucionales y de los pronunciamientos de las Cortes, el PPTP se vio en la necesidad de ajustar las herramientas y procedimientos de cada una de las rutas. La ruta étnica es ahora impulsada de la mano de instituciones como el IGAC, los catastros descentralizados, la Superintendencia de Notariado y Registro, el Incoder y las autoridades municipales y departamentales de las zonas en las que se realizarían las intervenciones. Por otro lado, en la tercera fase el proyecto introdujo entre sus líneas de acción la "Gestión, apoyo y acompañamiento a la formalización de los derechos sobre la tierra", con el propósito de avanzar hacia la seguridad jurídica de los derechos informales (Acción Social 2005e, pp. 85 a 95).

Así como ocurrió en la primera fase, la ejecución de experiencias piloto ayudó en el fortalecimiento de las herramientas. En esta tercera etapa se crea la línea de restitución en el interior del programa, que era el siguiente paso obligado en el quehacer del proyecto. Su coordinador fue la persona que hoy dirige la URT. En la misma dirección, se empiezan a pensar las figuras jurídicas que harían posible la restitución patrimonial, a lo cual se suma el contexto de justicia transicional abierto a partir de la Ley 975, que permite pensar en mecanismos fuera de la justicia ordinaria para hacer posible la devolución de los predios a los campesinos. Para la restitución el proyecto utilizó el mismo enfoque metodológico, ya que no había en el país antecedentes de ningún procedimiento de restitución de bienes. Sin embargo, para definir las rutas más importantes y útiles para las víctimas, en la fase tres se avanzó en cuatro aspectos: i) la definición de los criterios para seleccionar los casos, por ejemplo, la búsqueda de diversas situaciones de despojo que permitieran construir tipologías, ii) la focalización de zonas en las que se haya presentado incidencia de actores armados, iii) el diseño

15 Procesos adelantados con la Ley 975 o Ley de Justicia y Paz de 2005. 
de la estrategia de reparación y restitución con el apoyo de la comunidad $\mathrm{y}$ iv) seis pilotos de restitución.

Todos estos datos no fueron divulgados en su momento, suponemos que pudo obedecer a la estrategia de bajo perfil que venía manteniéndose. A pesar de este esfuerzo, su tarea en la protección de los predios y la detención de las compras masivas que se estaban presentando en zonas como los Montes de María hicieron que en el año 2009 se visibilizara su trabajo y se pusiera en cuestión por el gobierno de turno, llegándose incluso a temer por la subsistencia del proyecto. De hecho, si se pudo mantener fue gracias a que la financiación por parte del Banco Mundial estaba aprobada hasta 2012 y, desde luego, solo a finales de 2010 se empezaban a publicar algunas cifras.

Con respecto a los avances en la formulación de propuestas de política pública, se apoyó la formulación del Programa de Restitución de Bienes, dirigido por la Comisión Nacional de Reparación y Reconciliación. Además, los líderes del proyecto trabajaron de forma conjunta con el Ministerio del Interior y de Justicia en la elaboración de un proyecto de ley denominado "Acción de Restitución". Por último, se construyó un instrumento estadístico con el que se buscaba contrastar información institucional orientada a la focalización de los municipios, donde se adelantarían las acciones de restitución de bienes (Acción Social, 2010b). Todo lo anterior muestra que entre 2005 y 2009 ya se habían construido varios de los mecanismos para la restitución y que esta no había sido una creación de la Ley 1448 de 2011. Los informes del PPTP sobre los avances de la aplicación de las estrategias indican que al finalizar 2010 ninguna se había culminado, aunque sí se presentaron avances importantes en cuanto a la posibilidad para las víctimas de la restitución de sus derechos. Un aspecto que llama poderosamente la atención es que al final las bases de datos sí sirvieron para la restitución, ya que en la actualidad todo el archivo del proyecto es utilizado como materia probatoria. Por otro lado, no hay que desconocer el aprendizaje teórico y metodológico que dejó esta fase para los participantes del proyecto, que luego facilitaría la implementación de la Ley 1448.

Todo lo anterior explica la experticia que se había generado y que llevó a que el proyecto pasara en 2011 al Ministerio de Agricultura y que allí, en enero de 2012, se transformara en la Unidad de Restitución -lo cual tendrá efectos en la nueva institución, que empieza a ser cobijada por la 
Ley 80 y cofinanciada por el Estado-. En la transición se cambia la cabeza de la institución y se pasa de un perfil bajo, que se había mantenido hasta entonces, a tener gran visibilidad política y en los medios sobre el tema, aspecto este que no nos interesa analizar ahora, pero que sin duda es relevante puesto que transformó las lógicas que venían impulsando el proyecto objeto de este artículo.

A pesar de que la protección se ve relativamente truncada y de que se hace más incierto el futuro del RUPTA en el Incoder, las tablas 1 y 2 muestran que se avanzó en materia de protección y en la documentación de los casos - que hoy sirven como materia probatoria-. Este aspecto se refleja en las primeras sentencias de los jueces de tierras que surgen desde finales de $2012^{16}$ y sobre las cuales el proyecto ya tenía gran parte del sustento probatorio constituido. Resta ver si la protección se seguirá haciendo efectiva en los predios que sean despojados en la actualidad, ya que la dinámica, no lo olvidemos, continúa su paso.

\section{Balance de las políticas de protección y logros del PPTP}

\section{a) Avance en el análisis del contexto colombiano}

En varias de sus publicaciones el PPTP señaló que la primera medida para trabajar por una gestión integral que identificara, protegiera y regulara los derechos sobre la tierra y los territorios era realizar un análisis del contexto colombiano que se centrara en las dinámicas y evolución del desplazamiento, así como en el impacto del abandono, el despojo y la usurpación de las tierras de las víctimas (Acción Social, 2005e, 2010b). Como parte del trabajo de la red interinstitucional que consolidó el PPTP se realizó una caracterización del contexto colombiano, desarrollada a partir de consultorías - algunas de las cuales fueron publicadas-, específicamente sobre la magnitud y dinámicas del desplazamiento forzado, la distribución y uso de las tierras, la informalidad en la tenencia, la información y administración de tierras rurales, los grupos armados, y sobre otros casos internacionales

16 Sentencia de Manpuján de noviembre 2012, que beneficia a 23 familias. La vereda Balsillas en Tolima en febrero de 2013. 
de restitución (Acción Social, 2009, 2010b). Vemos aquí otro modus operandi de la cooperación internacional en su intento de dar valor agregado a la activación de políticas públicas a través de la contratación de expertos y estudios.

Dichos análisis producen cifras actualizadas y cartografías sobre los conflictos sociales y políticos, sobre la presencia de grupos armados ilegales, el cultivo y tráfico de sustancias ilícitas, la destrucción de recursos naturales renovables y no renovables, las violaciones a los derechos humanos, el desplazamiento forzado, la concentración de la propiedad agraria y la inequidad en el reparto de los ingresos rurales. Particularmente se trabajó en la identificación de las causas y tipologías del desplazamiento (Acción Social, 2009a). En la mayoría de sus publicaciones, el PPTP confirma la importancia política y social de la tierra en los negocios del narcotráfico y en el conflicto, al punto que determinan el ejercicio de su poder. La siguiente tabla expone las cifras de los principales departamentos expulsores de población entre los años 2005 y 2009, que muestran la mayor incidencia del fenómeno en las zonas de cultivo y salida de la droga:

Tabla 3. Coincidencia departamental entre expulsión y abandono

\begin{tabular}{|c|c|c|c|c|c|c|c|}
\hline \multirow{2}{*}{$\begin{array}{c}\text { Puesto } \\
\text { expulsor/ } \\
\text { RUPD }\end{array}$} & \multirow{2}{*}{$\begin{array}{c}\begin{array}{c}\text { Ubicación } \\
\text { del predio }\end{array} \\
\begin{array}{c}\text { Departa- } \\
\text { mento }\end{array}\end{array}$} & \multirow{2}{*}{$\begin{array}{c}\text { Hogares } \\
\text { expuelsados } \\
\text { RUPD }\end{array}$} & \multicolumn{4}{|c|}{ Abandono de tierras RUPTA } & \multirow{2}{*}{$\begin{array}{c}\text { Puesto de } \\
\text { Abando- } \\
\text { no/RUPTA }\end{array}$} \\
\hline & & & Derechos & Personas & Predios & Área (Has) & \\
\hline 1 & Antioquia & 108.807 & 6.641 & 5.452 & 6.532 & $282.237,51$ & 1 \\
\hline 2 & Bolivar & 56.482 & 4.056 & 3.714 & 3.993 & $184.978,30$ & 2 \\
\hline 3 & Magdalena & 45.769 & 1.351 & 1.216 & 1.318 & $61.957,04$ & 11 \\
\hline 4 & Chocó & 36.754 & 1.236 & 990 & 1.229 & $64.049,21$ & 12 \\
\hline 5 & Caquetá & 35.175 & 1.550 & 1.378 & 1.543 & $79.707,49$ & 5 \\
\hline 6 & Tolima & 34.774 & 1.973 & 1.552 & 1.915 & $39.942,25$ & 4 \\
\hline 7 & Cesar & 31.588 & 1.479 & 1.328 & 1.388 & $76.319,42$ & 8 \\
\hline 8 & Putumayo & 30.800 & 1.531 & 1.348 & 1.525 & $35.136,53$ & 6 \\
\hline 9 & Nariño & 29.852 & 1.516 & 1.200 & 1.511 & $32.004,11$ & 7 \\
\hline 10 & Cauca & 28.525 & 1.441 & 1.220 & 1.439 & $20.981,06$ & 9 \\
\hline 11 & Meta & 27.362 & 3.316 & 2.822 & 3.274 & $389.310,71$ & 3 \\
\hline
\end{tabular}




\begin{tabular}{|c|c|c|c|c|c|c|c|}
\hline \multirow{2}{*}{$\begin{array}{c}\text { Puesto } \\
\text { expulsor/ } \\
\text { RUPD }\end{array}$} & \multirow{2}{*}{\begin{tabular}{|c|}
$\begin{array}{c}\text { Ubicación } \\
\text { del predio }\end{array}$ \\
$\begin{array}{c}\text { Departa- } \\
\text { mento }\end{array}$
\end{tabular}} & \multirow{2}{*}{$\begin{array}{c}\text { Hogares } \\
\text { expuelsados } \\
\text { RUPD }\end{array}$} & \multicolumn{4}{|c|}{ Abandono de tierras RUPTA } & \multirow{2}{*}{$\begin{array}{c}\text { Puesto de } \\
\text { Abando- } \\
\text { no/RUPTA }\end{array}$} \\
\hline & & & Derechos & Personas & Predios & Área (Has) & \\
\hline 12 & $\begin{array}{l}\text { Valle del } \\
\text { Cauca }\end{array}$ & 27.245 & 841 & 705 & 835 & $32.967,28$ & 18 \\
\hline 13 & Cordoba & 24.195 & 1.207 & 1.099 & 1.090 & $34.855,21$ & 13 \\
\hline 14 & $\begin{array}{l}\text { Norte San- } \\
\text { tander }\end{array}$ & 21.866 & 1.401 & 1.174 & 1.382 & $59.662,86$ & 10 \\
\hline 15 & Sucre & 21.775 & 863 & 772 & 854 & $97.136,97$ & 17 \\
\hline 16 & Santander & 17.692 & 1.204 & 1.002 & 1.173 & $46.524,93$ & 14 \\
\hline 17 & Arauca & 14.057 & 888 & 759 & 880 & $110.813,05$ & 16 \\
\hline 18 & Caldas & 13.249 & 473 & 368 & 469 & $108.096,30$ & 21 \\
\hline 19 & Huila & 12.542 & 633 & 533 & 620 & $10.881,52$ & 19 \\
\hline 20 & La Guajira & 11.590 & 211 & 205 & 177 & $7.538,75$ & 23 \\
\hline 21 & $\begin{array}{l}\text { Cundina- } \\
\text { marca }\end{array}$ & 11.571 & 578 & 435 & 572 & $10.309,90$ & 20 \\
\hline 22 & Guaviare & 10.666 & 894 & 752 & 892 & $67.549,26$ & 15 \\
\hline 23 & Casanare & 5.885 & 154 & 135 & 151 & $31.164,63$ & 25 \\
\hline 24 & Risaralda & 4.128 & 173 & 137 & 170 & $9.431,95$ & 24 \\
\hline 25 & Vichada & 2.645 & 439 & 385 & 439 & $147.322,83$ & 22 \\
\hline
\end{tabular}

Datos: Registro Único de Población Desplazada (RUPD) - Acción Social y Registro Único de Predios y Territorios Abandonados (RUPTA), cálculos propios.

Fuente: Acción Social-PPTP, 2010b.

Según el Registro Único de Población Desplazada (RUPD), en Colombia, para el año 2009, "habían ingresado 750.881 hogares, que corresponden a 3’303.979 de personas internamente desplazadas, de las cuales 1'680.743 son hombres y 1'623.236 son mujeres, lo que equivale al 7,4\% del total de la población nacional proyectada por el DANE" (Acción Social, 2010) - una estimación bastante prudente si la comparamos con la de Codhes para las mismas fechas-.

Si se reunen los datos de las diferentes publicaciones, se puede concluir que los grupos étnicos y las comunidades negras representan el $11 \%$ de la población desplazada; el $8 \%$ corresponde a afrodescendientes y un $2 \%$ a 
comunidades indígenas. Además, la información estadística evidencia que el 98\% de la población desplazada proviene de las áreas rurales y en particular de los sectores más pobres (colonos, campesinos, negros e indígenas). Esta caracterización tiene una incidencia importante en la política para la restitución, que hace énfasis en estos grupos poblacionales, lo cual muestra la correlación entre los hallazgos del proyecto y los diseños de política pública del año 2011.

El desplazamiento ha estado vinculado al proceso de concentración de la tierra, razón por la cual el PPTP encontró necesario, como parte de su caracterización, hacer una revisión de los datos acerca de la distribución de propiedad rural. Los resultados mostraron que para el año 2002 el 47\% de los inmuebles hacía parte de la estructura minifundista y poseía áreas que sumadas constituían el 3,8\% del total nacional, mientras que el latifundio representaba para el año 2002 el 2,8\% de los predios, abarcando el 40\% del área total y, para 2008 representó el 0,16\% del total de los predios, es decir el 60\% del área (más territorio concentrado en menos manos) (Acción Social, 2005c). ${ }^{17}$ Debido a la poca difusión que se hizo de los hallazgos del proyecto por hacer parte del gobierno, el tema no fue visibilizado sino hasta la publicación del Informe de Desarrollo Humano de PNUD, en 2011, cuando se empiezan a prender las alarmas sobre la concentración de la tierra. Pero además del PPTP, autores como Ibáñez $(2004,2007,2009)$ y organizaciones de la sociedad civil habían visibilizado el problema. Todo lo cual muestra que únicamente bajo un gobierno favorable a la restitución el tema tendría una posibilidad de salir a la luz pública con la fuerza en que lo hizo en el 2011.

En las últimas publicaciones del PPTP se reconoce que no hay precisión sobre la magnitud del abandono, despojo y usurpación, ya que las cifras del RUPTA solo reflejan los predios que fueron registrados para la protección y se desconoce aún cuánta gente no tuvo acceso al registro, ni cuántos predios registrados no fueron objeto de una protección efectiva. ${ }^{18}$ Por otra

17 Con la publicación del Informe de Desarrollo Humano sobre tierras 2011 sabemos más sobre el acaparamiento de tierras fruto de este proceso. El informe afirma que el índice de Gini de tierras que muestra la desigualdad en la distribución es de 0,87. Uno de los más altos del mundo.

18 Hasta donde pudimos revisar, y en los documentos que tuvimos a nuestro alcance, no encontramos las cifras exactas de la protección efectiva de predios, es decir, cuando además de quedar registrado en el RUPTA, se registraba en el folio de matrícula inmobiliaria la prohibición de enajenación. 
parte, desarrollaron un panorama amplio sobre las distintas calidades de la propiedad. La siguiente gráfica muestra que las relaciones informales con la tierra se mantienen en más del 50\% del total de derechos protegidos (Acción Social, 2010b, p. 34), lo que llevó al PPTP a concluir que era necesario adelantar estrategias de titulación y saneamiento de la propiedad no solo para garantizar seguridad jurídica de los bienes afectados por la violencia, sino también mayor estabilidad socioeconómica de la población. Sin embargo, es importante mencionar que para los opositores de la Ley 1448 de 2011 la restitución de tierras, la cual garantiza únicamente que se devuelvan los títulos de propiedad de los predios, tiene como fin cumplir con las exigencias del Banco Mundial, acordes a las lógicas de extranjerización de las tierras y en algunos casos también podrá ser utilizada la titulación para legalizar los despojos (Robledo, debate en el Senado 20 de agosto de 2011).

Gráfica 2. Aplicación de medidas de protección, distribución de derechos según relación jurídica: rutas individual y colectiva. Consolidado nacional

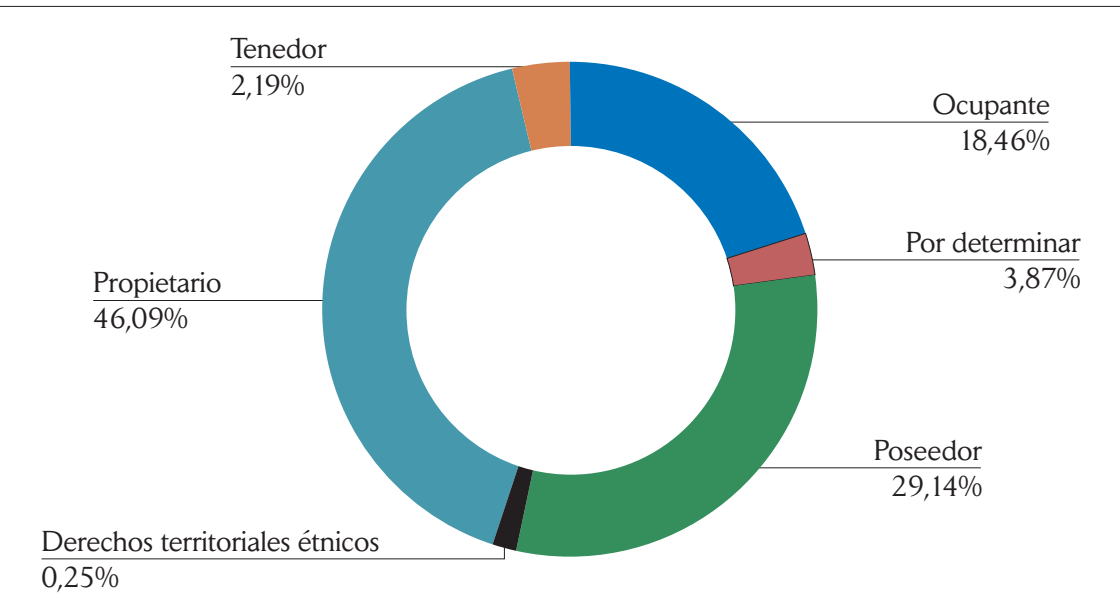

Fuente: RUPTA, SNR y CPTAID. Fecha de Corte: 31/07/2010.

La identificación de los grupos y dirigentes que ejercieron dominios territoriales durante la última década, desde 1996 hasta 2006, el estudio de su impacto en el desplazamiento y la descripción de los cambios en el acceso a tierras de la población rural tenían para el PPTP varios objetivos, a saber: presentar un estudio sencillo que permitiera a las comunidades desplazadas o en riesgo de desplazamiento, conocer su historia, el contex- 
to, los actores, las estructuras de oportunidad de resolución del conflicto y brindar algunas herramientas para identificar y transformar positivamente los conflictos por la tierra y el territorio, y así fortalecer sus capacidades en la defensa de sus derechos sobre estos (2005c, 2007).

Por otro lado, el PPTP utiliza la caracterización del contexto colombiano para contar con un mapa que oriente la localización de las acciones de recuperación de tierras por la justicia y el gobierno en beneficio de la población desplazada (Acción Social, 2009a, 2010b). Todos estos datos sirven hoy para la contextualización de los casos de restitución de tierras que son llevados ante el juez.

\section{b) Herramientas para la protección de los derechos patrimoniales de la población desplazada}

Dado que uno de nuestros objetivos es estudiar los instrumentos técnicos como herramientas para desarrollar procesos políticos, dedicaremos este aparte para revisar algunas de las propuestas del PPTP que permitieron el paso del concepto de protección al de restitución. El proyecto actuó en múltiples campos, incluyendo algunos que excedían su mandato, asumiendo el liderazgo en la red interinstitucional y acciones que correspondían a las instituciones según el Decreto 2007, específicamente el desarrollo del RUPTA, atender las solicitudes de protección en las regiones, capacitar a los funcionarios sobre las rutas y difundir la información entre las comunidades. Como vemos, el proyecto sobrepasó ampliamente a las instituciones que sin él difícilmente habrían avanzado en el cumplimiento de la norma. De nuevo, todo ello es posible gracias a la independencia del proyecto que lo dejaba fuera de las dinámicas y dificultades que conlleva pertenecer al Estado.

Es claro que se habrían podido diseñar mecanismos para proteger exclusivamente los predios que contaran con escritura pública, pero el gran problema eran los predios informales despojados, que eran la mayoría. Así, para poder realizar una protección efectiva se hizo necesaria la creación de instrumentos que facilitaran la formalización de predios en riesgo de ser abandonados. Lo mismo ocurrió con la restitución, si el proyecto y las personas que estaban allí comprometidas no hubieran creído en la posibilidad de devolución de los predios, seguramente no podríamos hablar hoy 
de restitución: al tiempo que en el proyecto se diseñaban las herramientas para la protección, ya se estaba pensando en las herramientas jurídicas para la restitución, que quedaron plasmadas en la Ley 1448 (la inversión de la carga de la prueba, los testimonios como material probatorio, etc.).

Otro de los aportes importantes del proyecto es su metodología de recolección inmediata de las experiencias, y de aplicación y validación constante en el terreno. En este sentido, la labor se concentró en el desarrollo de propuestas técnicas que siempre fueron retroalimentadas con casos reales, lo que implicó el desarrollo de diseños diferenciales con componentes étnicos y de género.

En cuanto a las comunidades negras, se hizo un estudio de caso y piloto en la región del Pacífico, por su "particular forma de organización étnica para la apropiación y ordenamiento territorial y, desde la década anterior, se encuentra altamente afectada por el desplazamiento forzado" (Acción Social, 2005a, pp. 10, 11). A partir de la caracterización que se hizo en cuatro zonas de la región, se concluyó que los principales factores que amenazan la estabilidad de los territorios étnicos y que configuran su estado de vulnerabilidad en el marco de conflicto y desplazamiento forzado son "el debilitamiento interno y externo de la capacidad de gestión y respuesta de las organizaciones y autoridades étnicas, y la baja apropiación de la legislación étnica por parte de los pobladores, así como de las entidades competentes en la protección" (Acción Social, 2005d, p.3). Con los resultados se desarrolla la cartilla Comunidades negras, en la que se divulgan los derechos de estas comunidades en relación con el territorio y los mecanismos legales para su protección, en asocio con las juntas de los consejos comunitarios de las zonas focalizadas. Para el caso de los grupos indígenas, el proyecto trabajó directamente con las organizaciones, los líderes y las autoridades indígenas. El texto producto de esta aproximación se concentró en el alcance de los derechos de los pueblos indígenas en materia de territorio. En palabras de los autores: "En este cuaderno de trabajo conoceremos el alcance de los derechos territoriales indígenas y los límites que impone su relación con el ordenamiento jurídico nacional, de acuerdo con las sentencias que sobre la materia han expedido las altas cortes" (Acción Social, 2005d, p.3). El documento reúne hallazgos y estudios realizados en las comunidades indígenas del Pacífico, así como las denuncias de los líderes de las mismas, retoma sus derechos a partir de la jurisdicción especial indígena y expone 
los mecanismos para la protección de las tierras colectivas. Por otro lado, la jurisdicción especial indígena sugiere que "Las comunidades indígenas son sujetos de derechos y obligaciones, por medio de sus autoridades ejercen poder sobre los miembros que las integran hasta el extremo de adoptar su propia modalidad de gobierno y ejercer control sociall". ${ }^{19}$ Los derechos territoriales para los pueblos indígenas en la Constitución son normas superiores dentro del ordenamiento jurídico nacional (Acción Social, 2005d, p. 4). Así, se reconocen como sujetos de atención especial frente al fenómeno del desplazamiento forzado. Entre las principales razones se encuentran que alrededor del 8\% de los inscritos en el Registro Único de Población Desplazada son indígenas y, en segundo lugar, que "el desplazamiento forzado conlleva un impacto desproporcionado sobre el ejercicio de los derechos fundamentales y vulnera particularmente los derechos territoriales de los grupos étnicos" (Acción social, 2005d, p. 7).

Para el enfoque diferencial de género, el PPTP diseñó tres estrategias: 1) hacer visibles los derechos patrimoniales de las mujeres a través de rutas y procedimientos; 2) capacitaciones a nivel institucional sobre el enfoque diferencial; 3) construir, con apoyo del IGAC, un aplicativo web en el que se expuso "La cartografía de vulnerabilidad sobre la tenencia de la tierra en las mujeres víctimas del desplazamiento forzado", cumpliendo con lo dispuesto por la Corte Constitucional en los autos 092 y 237 de 2008; 4) construir herramientas y estrategias de intervención que fueron implementadas en las actividades comunitarias de capacitación con líderes y lideresas de la población en riesgo y en situación de desplazamiento. A pesar de la estrategia, es significativa la desproporción en la protección de derechos de las mujeres con relación a los hombres: el 33,48\% corresponde a mujeres y el 65,35\% a hombres, lo que muestra que aunque el proyecto insistió en el reconocimiento equilibrado de los derechos, la salvaguarda de los mismos no ha sido equitativa.

19 Sentencia de Tutela 380 del 14 de octubre de 1993, M.P.: Eduardo Cifuentes Muñoz; Sentencia de Tutela 254 del 30 de mayo de 1994, M.P.: Eduardo Cifuentes Muñoz. 
Gráfica 3. Derechos cobijados según género: rutas individual y colectiva 20032010

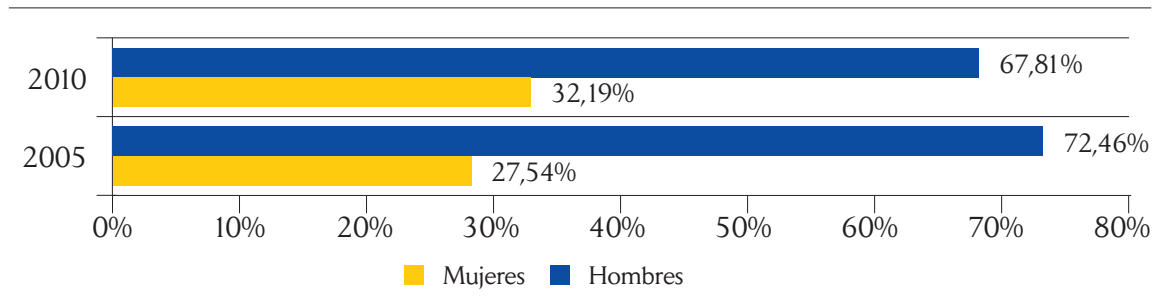

Fuente: Acción Social-PPTP (2010c, p. 29). Sintesis de la experiencia del Proyecto de Protección de Tierras y Patrimonio de la Población Desplazada.

\section{c) Logros puntuales de la politica de protección}

Desde el año 2003 y hasta finalizar el 2010 la aplicación de las medidas de protección tuvo un avance significativo, ya que se consiguió incrementar la demanda por parte de las víctimas. "En diciembre de 2010 se habían protegido 148.263 derechos ejercidos por 115.888 personas en 120.101 predios asociados a una extensión estimada de 4'750.185,60 hectáreas, los cuales se localizan en 882 municipios del país" (Acción Social, 2010b, p. 52 ). De estos derechos, el $46,36 \%$ corresponde a propiedades, el $28,67 \%$ son los poseedores y sus asociados, mientras que el $18,59 \%$ se relaciona con ocupantes de baldíos.

Tales cifras indican que existe la necesidad de adelantar estrategias complementarias de titulación y saneamiento de la propiedad, ya que las relaciones informales con la tierra se mantienen, por lo menos, en un 50\% del total de derechos protegidos. Con ello se lograría mayor estabilidad económica de la población, así como seguridad jurídica para los bienes afectados por la violencia. En el siguiente mapa observamos la distribución de la aplicación de las medidas de protección en el territorio nacional:

Por otro lado, en los resultados de la aplicación de las medidas de protección el PPTP observó que "no existe una relación uno a uno entre derechos y predio, ni entre predios y personas". En la ruta colectiva, esta relación es significativa ya que en los casos de poseedores se registra un $29 \%$ más de derechos que de predios, y en ocupantes un $17 \%$ más.

Atendiendo a la participación de personas, a finales del año 2010 se registraron solicitudes de protección en 31 de los 32 departamentos del 
país, "siendo Antioquia el de mayor participación con 17,67\%, seguido por Bolívar con un $11,12 \%$, Meta con un 8,76\%, Tolima con un 5,18\%, también Magdalena, Putumayo, Cesar y Caquetá, cada uno con 4,1\%. En los demás casos se registran participaciones menores al 4\%" (Acción Social, 2010c, pp. 20,21). Las anteriores cifras dan cuenta de los lugares donde se presentaron más desplazamientos en correspondencia con las zonas donde el proyecto de protección adelantó su trabajo de asesoría y capacitación a través de los equipos regionales.

Los hallazgos en cuanto a las extensiones o áreas protegidas fueron en total 4'750.185 hectáreas. En la distribución según el tamaño de los predios el PPTP encontró que

[...] el 24,71\% corresponde a lotes menores de 5 hectáreas; el 30,62\% son medianas extensiones de 5 a 50 hectáreas; el 10,89\% son extensiones de más de 50 hectáreas; y no se ha establecido la extensión del 33,05\% de los predios; solo un $0,73 \%$ corresponde a 871 predios cuya área se reporta por fuera de cualquier rango catastral, (lo que puede ser un error)" (Acción Social, 2010c, p. 18).

Es importante reconstruir estos datos porque en las rutas individual y colectiva el mayor porcentaje de predios se encuentra en los rangos de superficie correspondiente a minifundios y propiedades de mediano tamaño.

Sin embargo, debemos ser cuidadosos con las cifras ya que el PPTP adelantó un trabajo significativo con 148.263 solicitudes de protección diligenciadas $\mathrm{y}$, a la vista del mismo, la cifra debe ser puesta en perspectiva en dos aspectos: primero, porque no todas las solicitudes diligenciadas contaron con una protección efectiva -y esta cifra no es publicada en sus documentos- $y$, segundo, porque las solicitudes de protección también fueron reducidas si se comparan con las estimaciones reales del despojo. Codhes habla de una cifra de aproximadamente un millón de hogares, lo cual nos haría pensar que si al menos la mitad ocupaba un predio, la cifra debe estar cerca de los 500.000 predios abandonados, y no 300.000 co- $^{-}$ mo afirma el gobierno.

Como ejemplo de lo residual que sigue siendo esta política, en Carmen de Bolívar, uno de los municipios con mayor población desplazada, para el año 2001 se habían desplazado 27.000 personas, en el periodo de 2003 a 


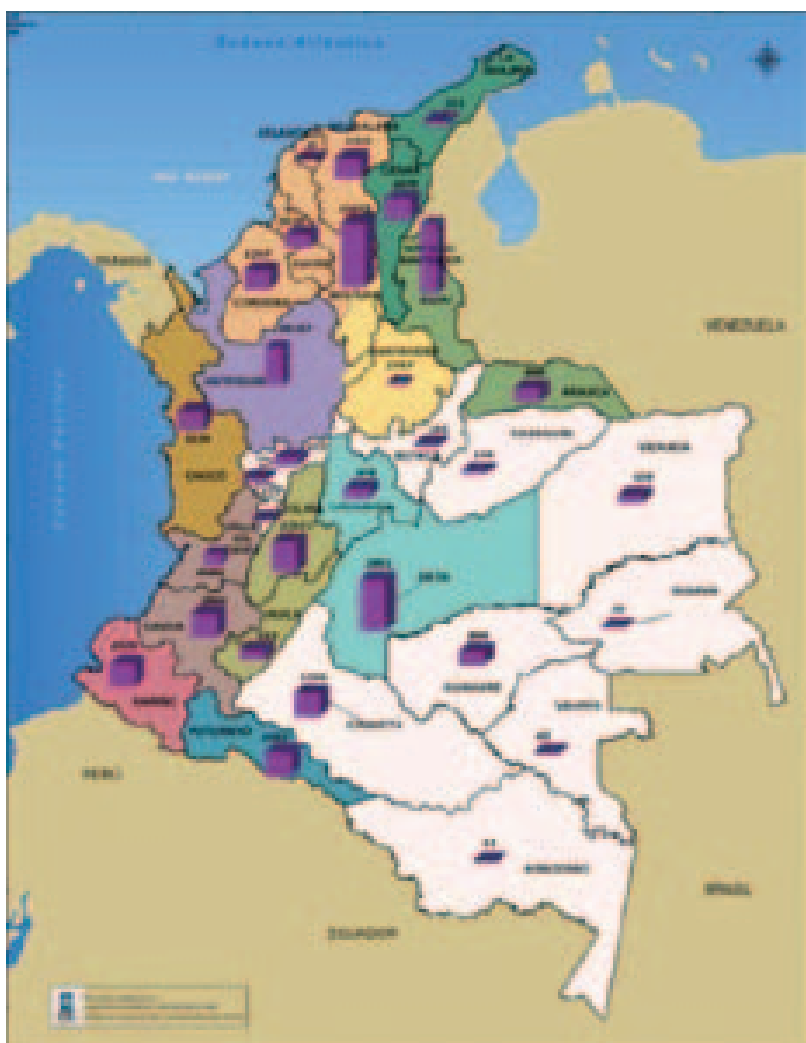

\section{Símbolo \\ CONVENCIONES \\ Número de Derechos}

\begin{tabular}{|l|}
\hline \multicolumn{2}{|c|}{ Región } \\
\hline Antioquia \\
\hline Caribe \\
\hline Guajira-Cesar \\
\hline Centro \\
\hline Chocó \\
\hline Nariño \\
\hline Nte. Santander-Arauca \\
\hline Santander-Magdalena Medio \\
\hline Tolima-Huila \\
\hline U.G. Nacional \\
\hline Valle del Cauca-Cauca \\
\hline Putumayo \\
\hline \multicolumn{2}{|c|}{ Área protegida en Colombia: } \\
3624239.289 (Ha) \\
\hline \multicolumn{2}{|c|}{} \\
\hline
\end{tabular}

Fuente: Acción Social- PPTP, 2010c.

\begin{tabular}{|l|c||l|c|}
\hline Departamentos & $N^{\circ}$ Derechos & Departamentos & $N^{\circ}$ Derechos \\
Amazonas & 11 & Huila & 633 \\
Antioquia & 29,197 & La Guajira & 211 \\
\hline Arauca & 888 & Magdalena & 1,351 \\
\hline Atlantico & 35 & Meta & 3,891 \\
\hline Bogotá D.C. & 19 & Nariño & 2,528 \\
\hline Bolívar & 10,655 & Norte Santander & 52,292 \\
\hline Boyacá & 105 & Putumayo & 1,531 \\
\hline Caldas & 473 & Quindío & 38 \\
\hline Caquetá & 1,550 & Risaralda & 173 \\
\hline Casanare & 154 & Santander & 2,757 \\
\hline Cauca & 2,866 & Sin información & 1,031 \\
\hline Cesar & 1,479 & Sucre & 2,029 \\
\hline Choco & 1,236 & Tolima & 12,611 \\
\hline Córdoba & 1,207 & Valle del Cauca & 9,986 \\
\hline Cundinamarca & 578 & Vaupés & 45 \\
\hline Guainia & 38 & Vichada & 439 \\
\hline Guaviare & 894 & Total General & 142,931 \\
\hline
\end{tabular}


$2008^{20}$ se desplazaron 18.790 más, con lo que la cifra ascendería a cerca de 50.000 desplazados en un solo municipio (Acción Social, 2009c). Dicho registro representa la tercera parte del total de solicitudes recibidas a nivel nacional, con lo que se demuestra que las solicitudes no reflejan la magnitud del despojo. Siguiendo el mismo ejemplo, la URT calcula hoy que en este municipio deben ser restituidas más de 4'000.000 de hectáreas, dato que, comparado con el total de las hectáreas protegidas por el PPTP - que fue de 4'750.185 hectáreas en todo el país- evidencia que la magnitud del fenómeno fue muy superior a lo que cuantificara el proyecto.

Para los casos de ruta colectiva, los avances en la información de los predios protegidos reflejan que existen muchos predios en los que no se ha podido definir su extensión, ya sea por no haber información catastral ni en los registros institucionales locales o porque los casos fueron registrados por las comunidades. En la ruta de protección individual la situación fue parecida. El panorama anterior alertó al equipo del PPTP sobre la alta informalidad en las relaciones jurídicas con la tierra, llevándolos a concluir que era necesario modificar las políticas públicas para que la nación pudiera crear folios a su nombre y avanzar en procedimientos especiales para la formalización de los derechos para la población en situación de desplazamiento.

Los avances que se han recogido y sintetizado muestran la manera en que el proyecto asume su responsabilidad frente a su mandato y lo excede, desarrollando los instrumentos necesarios para hacer posible la restitución, lo cual estaba lejos de sus lineamientos y funciones. Todo ello tiene lugar en un escenario en el que la agenda política del proyecto no estaba orientada por la agenda del gobierno de turno. No está de más redundar en tres aspectos que son fundamentales para el desarrollo de la propuesta y su avance: por una parte, el bajo perfil que mantuvo frente al gobierno e incluso frente a las autoridades locales, la estrategia metodológica de trabajar a partir de los casos, y no solo de la normatividad vigente, y, finalmente, el mantenimiento de un perfil técnico que le permitió su posición de interventor financiado por la cooperación internacional. Estos avances también muestran que la agenda política de 2011 sobre la restitución ya había sido definida desde antes con mecanismos técnicos y por la voluntad de un grupo de funcionarios, constituyéndose en un ejemplo particular

20 No contamos con la cifra de 2002. 


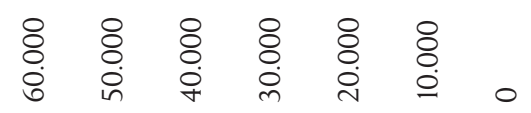

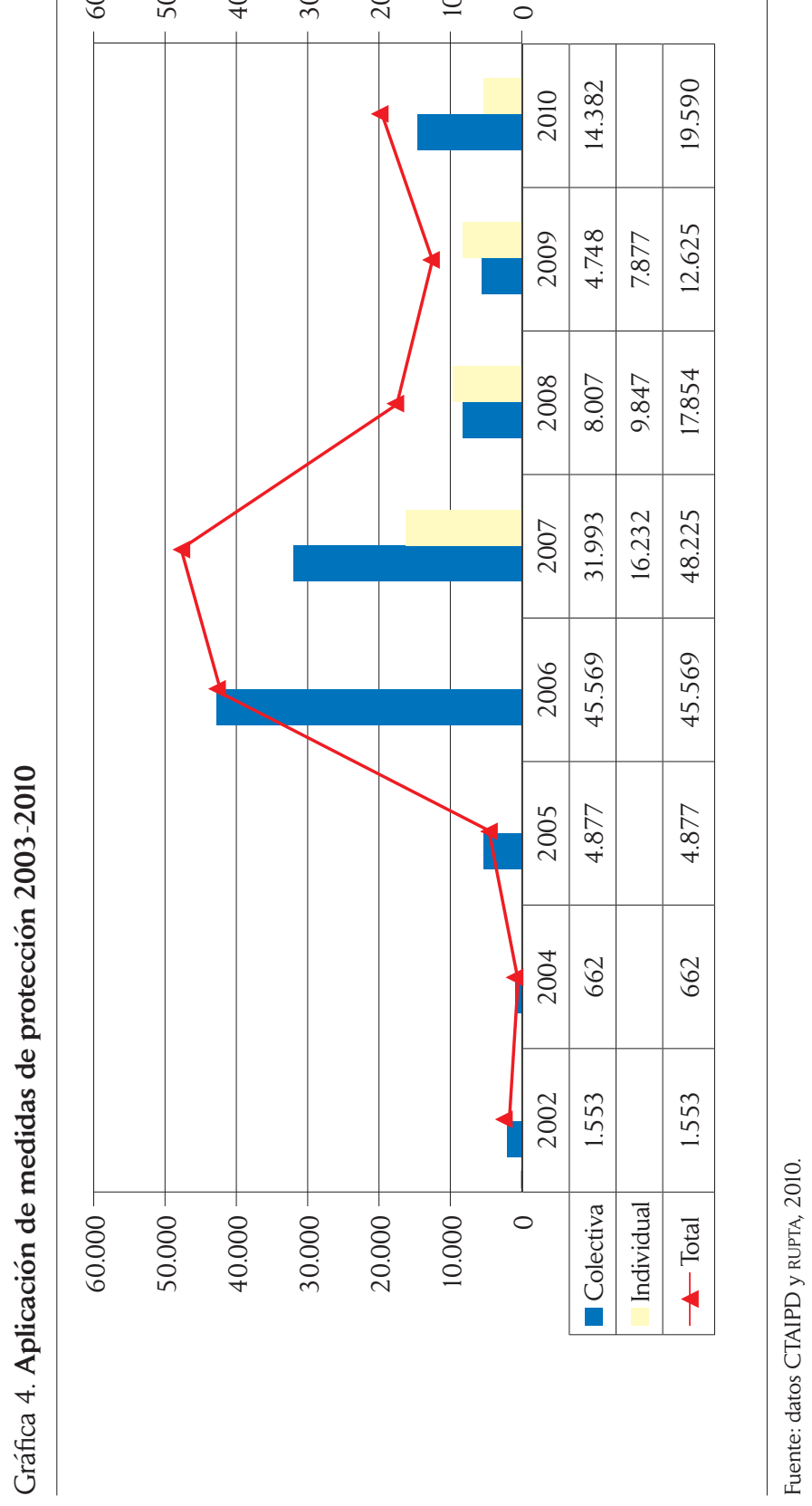

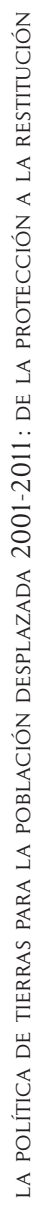

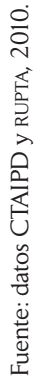


que permite analizar otras formas de gubernamentalidad, como se señaló en la introducción.

\section{Conclusiones}

Hemos intentado reconstruir la trayectoria institucional del PPTP durante los diez años de su funcionamiento, mostrar los avances técnicos que se produjeron en materia de protección de tierras y sus aportes en el cumplimiento de la normativa, que en algunos casos la excede. Este ejercicio nos parece importante dada la dispersión de los datos y la poca visibilidad que tuvo el proyecto, hecho que, como ya hemos visto, hizo parte de una estrategia de bajo perfil necesaria para sobrevivir en el gobierno de turno. Por otra parte, el proyecto es un ejemplo interesante y particular de institucionalidad pública que contrasta con las otras instituciones del sector, por lo cual merece ser analizado desde la perspectiva de los actores por el papel que jugaron los funcionarios en el proceso.

Dado que hoy la política de restitución es una realidad, es interesante entender su génesis y evolución. Como hemos mostrado, la URT no arranca de cero en 2011, lo cual explica el hecho de que rápidamente se haya puesto en marcha. Sin embargo, el gobierno y la Unidad fueron muy optimistas al delimitar sus metas, pues ni los procesos han sido tan fáciles, ni el avance de la restitución, ágil. Hoy, tras dos años, solo se cuenta con 230 sentencias de restitución, muy lejos de la meta de 350.000 procesos en los diez años de vigencia con los que se comprometió el gobierno.

Retornando al proyecto, es de señalar que jugó un papel importante en la articulación institucional aunque también asumió funciones que correspondían a las instituciones, por lo que enfatizamos que quizás sin él la política de protección habría sido difícilmente puesta en marcha. Técnicamente favoreció el desarrollo de herramientas que facilitarían la comprensión de la compleja problemática del despojo a través de instrumentos jurídicos y sistemas de información.

Merecen destacarse los procesos de aprendizaje institucional, así como de formación de personal dentro del proyecto y en las instituciones encargadas de la protección. Lo anterior posibilitó, entre otras cosas, que seis meses después de formulada la Ley 1448 se pusiera en marcha la Unidad 
de Restitución de Tierras, es decir, la base conceptual y la experiencia que tenía el proyecto fue el mecanismo facilitador de la política de restitución. Si se compara la aplicación de la Ley 387 con la de la Ley 1448 se identifican claramente las diferencias. El decreto reglamentario para la protección de bienes tardó cuatro años en producirse; el registro, siete; y la protección efectiva, ocho años. En lo que respecta a la Ley 1448, los decretos reglamentarios salieron seis meses después de su ratificación, tiempo récord que solo se explica por el hecho de la transformación del PPTP en URT. Así, las políticas de protección y restitución de tierras se encuentran entrelazadas y paulatinamente la protección permite el desarrollo del concepto de restitución. Lo que hemos resaltado a lo largo de esta reconstrucción es el papel singular de los funcionarios a cargo y del organismo financiador, quienes desde el inicio pensaron la protección como un medio para hacer posible la restitución.

Sin embargo, en este proceso de transición de la Ley 387 a la 1448 se borra la categoría de desplazado y, con ella, gran parte de los avances jurídicos, en atención a que se habían logrado entre 1997 y 2010. El paso de la categoría de "desplazado" a "víctima" significa una conceptualización diferente de los sujetos sobre los cuales se gobierna, y va a tener efectos significativos en ellos. Este es un aspecto que queda por analizar, quizás en otras investigaciones, donde se estudien los procesos de subjetivación en el paso de una categoría a otra, desde la perspectiva de las víctimas.

Finalmente, reconstruimos el proceso estratégico por el cual el proyecto se conduce con un bajo perfil frente al gobierno anterior, manteniendo las lógicas de la cooperación internacional, que, como vimos, defiende el discurso de la neutralidad y le permite mostrar un trabajo técnico que protege el contenido político de la agenda del financiador. Vemos así cómo las diferentes lógicas de gubernamentalidad desatan "alianzas" y "redes", formadas por las autoridades políticas y otros actores, para gobernar y explicar de qué manera la colaboración entre la elite estatal y grupos independientes de la sociedad civil aumentan el poder del Estado (Haidar, 2005, p. 242), y cómo ellos van configurando intereses que facilitan o limitan la construcción de una política de restitución en este caso. Estos procesos políticos pasan además por las personas que cotidianamente se dedican a pensar las respuestas técnicas y las soluciones a las problemáticas que se van presentando, y que luego se van convirtiendo en estrategias políticas: 
Necesitamos investigar en el espacio gris de las ciencias, de las profesiones menores, de los contadores y aseguradores, los gerentes y psicólogos, en el mundano negocio del gobierno económico y social de la vida cotidiana, en la conformación de los dominios del gobierno y de las personas gobernables, en las nuevas formas de poder, autoridad y subjetividad que están siendo formadas en las prácticas mundanas (Rosse, Malley y Valverde, 2006, p. 101).

La idea ha sido analizar los micro-espacios de construcción del poder, como hemos intentado hacer a través de la trayectoria institucional. Todo ello se complementará con el estudio de los testimonios de las personas que participaron en este proceso, lo que permitirá clarificar los roles de cada uno, las interconexiones entre ellos y las distintas agendas de gubernamentalidad. Sin embargo, podemos ver cómo las políticas de tierras, entendidas como políticas de Estado, si bien son procesos en las instituciones, no están situadas exclusivamente en ellas, sino que van más allá, incluso enmarcándose en un espacio político global.

Otro de los hallazgos importantes de este análisis es el de develar cómo el Estado es superado en dos dimensiones, una micro y otra macro. En la micro, el PPTP sobrepasa algunas de las funciones de otras instituciones del Estado, ya que estas no están en capacidad de organizarse para cumplir con el mandato de la reglamentación de la Ley 387. El PPTP excede la normatividad al desarrollar la articulación, las herramientas y la atención en campo y lo hace justamente por ser una institución atípica que funciona con otras reglas. Todo ello demuestra la incapacidad de las estructuras y lógicas tradicionales del Estado colombiano para actuar frente a la problemática. En la dimensión macro, el Estado es superado por las lógicas de los organismos financiadores del PPTP al apuntar a favorecer una agenda internacional de defensa y restablecimiento de los derechos de las víctimas, pero que también beneficia la legalización de las compras de tierras que ocurrieron en estos periodos que, como es sabido, terminaron por beneficiar la extranjerización. Ello sustenta la afirmación de Trouillot (2001) sobre la dificultad de los Estados nacionales contemporáneos para contener una lógica de gobierno homogénea.

En cuanto a los datos que hemos presentado, si bien el PPTP favoreció la protección y produjo avances importantes, sus alcances con respecto a 
la magnitud del fenómeno son limitados. Los cerca de 140.000 predios que lograron ser protegidos son menos de la mitad de los 300.000 que el mismo gobierno acepta fueron objeto de despojo -y sabemos que es una cifra que excluye todos los predios que no han sido declarados, que podrían llegar a 500.000-. Esto nos enseña que, aunque existieran los mecanismos y la voluntad de parte de los funcionarios del proyecto, la continuidad del conflicto, la falta de información de los campesinos, las dinámicas de poder local y finalmente el miedo, fueron y siguen siendo obstáculos mayores para el objetivo de alcanzar una mayor cobertura.

De igual manera, a pesar de tener una sistematización juiciosa de los avances los documentos no contemplan una perspectiva crítica, ni dan datos que permitan entender las dificultades del proceso. Esto puede relacionarse con el hecho de que su funcionamiento dependía de los resultados mostrados al financiador, hecho que ocurre en casi todos los informes de gestión de proyectos, en los cuales se minimizan los efectos negativos y se valoran los avances para sostener la intervención (Rodríguez, 2012). Se trata de una de las grandes limitaciones del material analizado para esa parte inicial de la investigación, pero no significa que no hubiese una reflexión crítica que se manifiesta en algunos de los testimonios orales y que queda por explorar.

Otro de los vacíos importantes del corpus de datos documental estudiado es la dificultad de plasmar en el material publicado las herramientas puntuales y los procesos de construcción de las mismas, cómo se negocian, se adaptan y se llevan a terreno. En particular, queremos señalar una laguna en la documentación de los enfoques diferenciales que de manera discursiva se presenta en todos los documentos. Si bien se hace claramente visible la problemática, en la práctica no se ve tan clara la diferenciación, atribuible en parte también a la memoria de los funcionarios. En este sentido, por ahora los enfoques diferenciales parecen más una construcción discursiva. Resta contrastar con las prácticas.

Quedan así muchas preguntas abiertas que seguramente el análisis testimonial completará para lograr reconstruir el proceso político y todas las dimensiones de construcción de la política de restitución de tierras. Sin embargo, este primer recuento nos permite hacer un balance interesante, recoger la experiencia, además de proveer datos que no habían sido sacados a la luz por la institución y que, en el contexto político en el que los avances del proyecto se produjeron, limitaron mucho su difusión y conocimiento. 


\section{Referencias}

\section{Bibliográficas}

Bejarano, J., Echandía, C., Escobedo, R. y León, E. (1997). Colombia: inseguridad, violencia y desempeño económico en las áreas rurales. Bogotá: Universidad Externado de Colombia, Fonade.

Codhes (2011, 15 de febrero). Boletín Informativo de la Consultoría para los Derechos Humanos y el Desplazamiento, 77. Recuperado de http://www.rebelion.org/ docs/130767.pdf

Codhes-UnICEF (1999). Un país que huye. Desplazamiento y violencia en una nación fragmentada". Bogotá: Codhes.

Foucault, M. (1988). El sujeto y el poder. En H. L. Dreyfus y Rabinow (ed.).Más allá del Estructuralismo y la Hermenéutica. México: Editorial Universidad Autónoma de México.

García, P. (2011). La paz perdida. Territorios colectivos, palma africana y conflicto armado en el Pacífico colombiano. México: FLACSO. Recuperado de http://www.flacso.edu.mx/ biblioiberoamericana/TEXT/DOCCS_VII_promocion_2008-2011/Garcia_P.pdf

Grinberg, S. M. (2007). Gubernamentalidad: estudios y perspectivas. Revista Argentina de Sociología, 5(8), 95-110.

Gutiérrez Sanín, F. (2012).Una relación especial: privatización de la seguridad, élites vulnerables y sistema político colombiano (1982-2002). Estudios Socio-Jurídicos, 14(1), 97-134.

Haidar, V. (2005, abril). El 'descentramiento' del Estado en el análisis del poder (político): Un diálogo crítico entre la sociología histórica y el enfoque de la gubernamentalidad. Espacio Abierto, 14 (2), 239-264. Recuperado de http://www2.scielo. org.ve/scielo.php?script=sci_arttextEpid $=$ S1315-00062005000200003Elng $=\mathrm{e}$ sEnrm=iso

Ibáñez, A.M. (2009). Los programas de retorno para la población desplazada en Colombia. En C. Rodríguez (ed.). Más allá del desplazamiento: políticas, derechos y superación del desplazamiento forzado en Colombia. Bogotá, Colombia: Editorial Uniandes.

Ibáñez, A. M. y Engel, S. (2007). Displacement Due to Violence in Colombia: A Household Level Analysis. Economic Development and Cultural Change 55(2), 335-365. Ibáñez, A.M. y Querubín, P. (2004). Acceso a tierras y desplazamiento forzado en Colombia. Bogotá: Universidad de los Andes, CEDE. 
Ibáñez, A. M. y Vélez, C.E. (2003). Forced Displacement in Colombia: Causality and Welfare Loses. Bogotá: Editorial Universidad de los Andes y Banco Mundial.

Machado, A. (2004a). Estado del arte sobre la producción académica en el sector rural 1986-2003. Bogotá: Universidad Nacional de Colombia, Centro de investigaciones para el Desarrollo, CID.

Machado, A. (2004b). Tenencia de la tierra, problema agrario y conflicto. En Desplazamiento forzado: Dinámicas de guerra, exclusión y desarraigo (pp. 52-68). Bogotá: Acnur - Universidad Nacional de Colombia.

Machado, A. (2009). La reforma rural, una deuda social y politica. Bogotá: Universidad Nacional de Colombia, CID.

Miller, P. y Rose, N. (1990, febrero). Governing Economic Life. En Economy and Society, 19(1), 1-31.

Pécaut, D. (2001). Guerra contra la sociedad. Bogotá: Espasa.

Pérez Murcia, L. E. (2004). Factores asociados al desplazamiento forzado en Colombia. En M. N. Bello (ed.). Desplazamiento forzado. Dinámicas de guerra, exclusión y desarraigo (pp. 43-59). Bogotá: Universidad Nacional de Colombia.

Programa de las Naciones Unidas para el Desarrollo PNUD (2011). Desplazamiento forzado tierras y territorios. Agendas pendientes: la estabilización socioeconómica y la reparación, Bogotá: INDH.

Rodríguez, N. (2012). Transformar y comprender: retos de las ciencias sociales. Revista de Ciencias Sociales (en prensa).

Rose, N., Oêmalley, P. y Valverde, M. (2006). Govern mentality. Annual Review of Law and Social Science, 2, 83-104.

Rose, N. y Miller, P. (1992).Political Power beyond the State: Problematics of Government. The British Journal of Sociology, 43(2), 173-205.

Sánchez, F. (2007). Las cuentas de la violencia: ensayos económicos sobre el conflicto y el crimen en Colombia. Bogotá: Norma.

Sánchez, G. y Peñaranda, R. (2007). Pasado y presente de la violencia en Colombia. Medellín: La Carreta.

Sarmiento, L. (2000). Desarrollo societal, conflicto y territorio. En Seminario Internacional Desplazamiento, conflicto, paz y desarrollo. Ponencia. Bogotá: Codhes.

Swarttz, M., Turner, V. W. y Tuden, A. (1996). Introduction. En Political Anthropology. Chicago: Aldine Press.

Tovar, H. (2001). Emigración y éxodo en la historia de Colombia. Migrations en Colombie, Cahiers Alhim (3). Recuperado de http://alhim.revues.org/document522.html 
Trouillot, M. R. (2001). The Anthropology of the State in the Age of Globalization: Close Encounters of the Deceptive. Current Anthropology, 42(1), 125-138.

Trouillot, M. R. (2011). Transformaciones globales: La antropología y el mundo moderno. Popayán: Editorial Universidad del Cauca.

Villa, M. I. (2006). Desplazamiento forzado en Colombia. El miedo: un eje transversal del éxodo y de la lucha por la ciudadanía.

\section{Documentos PPTP}

Acción Social-PPTP (2005a). Comunidades negras. Bogotá: Presidencia de la República. Acción Social-PPTP (2005b). Gente de esteros, ríos y mar: zonificación para la protección del territorio colectivo de ACAPA. Bogotá: Presidencia de la República.

Acción Social-PPTP (2005c). Guía de sensibilización y formación para la protección de los derechos sobre la tierra. Bogotá: Presidencia de la República.

Acción Social-PPTP (2005d). Derechos territoriales de los pueblos indígenas: Elementos de la legislación especial indígena en materia de derechos territoriales. Bogotá: Presidencia de la República.

Acción Social-PPTP (2005 e). La experiencia colombiana en la salvaguarda de los derechos patrimoniales de las personas desplazadas internamente en contextos de violencia. Bogotá: Presidencia de la República.

Acción Social-PPTP (2007). Capacitación comunitaria en la identificación, la caracterización y el tratamiento de conflictos por la tierra y el territorio. Guía para facilitadores. Bogotá: Presidencia de la República.

Acción Social-PPTP (2008). Desarrollo del proceso de enajenación o transferencia de derechos sobre predios ubicados en zonas de declaratoria de riesgo de desplazamiento o de desplazamiento. Bogotá: Presidencia de la República.

Acción Social-PPTP (2009). Del abandono al despojo: de cómo se han afectado los derechos patrimoniales de las víctimas del desplazamiento forzado, según sus declaraciones para el proceso de justicia y paz. Bogotá: Presidencia de la República.

Acción Social-PPTP (2009a). Identificación de los agentes colectivos responsables del abandono de tierras en los municipios colombianos. Bogotá: Presidencia de la República. Acción Social-PPTP (2010). Notas sobre el derecho a la restitución y experiencias internacionales de restitución de bienes. Bogotá: Presidencia de la República.

Acción Social-PPTP (2010a). Experiencia de documentación y recuperación de tierras abandonadas y despojadas con ocasión del conflicto armado. Bogotá: Presidencia de la República. 
Acción Social-PPTP (2010b). La protección de tierras y territorios para la salvaguarda de los derechos patrimoniales de las víctimas. Bogotá: Presidencia de la República.

Acción Social-PPTP (2010c). Síntesis de la experiencia del Proyecto de Protección de Tierras y Patrimonio de la Población Desplazada. Bogotá: Presidencia de la República.

\section{Leyes y decretos}

Corte Constitucional de Colombia (2003). Sentencia T-025. Magistrado ponente: Jaime Araújo. Bogotá.

Corte Constitucional de Colombia (2008). Auto 092. Magistrado ponente: Manuel José Cepeda. Bogotá.

Corte Constitucional de Colombia (2008). Auto 237. Magistrado ponente: Manuel José Cepeda. Bogotá.

Corte Constitucional de Colombia (2009). Auto 004. Magistrado ponente: Manuel José Cepeda. Bogotá.

Corte Constitucional de Colombia (2009). Auto 005. Magistrado ponente: Manuel José Cepeda. Bogotá.

Colombia. Congreso de la República (1994). Ley de Reforma Agraria, Ley 160. Recuperado de http://www.incoder.gov.co/documentos/Ley160_2004.pdf

Colombia. Congreso de la República (1997). Ley de Desplazamiento Forzado, Ley 387. Recuperado de http://www.brookings.edu/ /media/Projects/idp/Colombia_Ley387_1997_Span.PDF

Colombia. Congreso de la República (2005). Ley de Justicia y Paz, Ley 975. Recuperado de http://www.semana.com/documents/Doc-1246_2006518.pdf

Colombia. Congreso de la República (2007). Ley de Estatuto de Desarrollo Rural, reforma el Instituto Colombiano de Colombia. Bogotá: Diario Oficial.

Colombia. Congreso de la República (2007). Ley 1152. Recuperado de http://www. acnur.org/biblioteca/pdf/5344.pdf?view=1

Colombia. Congreso de la República (2011). Ley de Víctimas, Ley 1448. Recuperado de http://www.leydevictimas.gov.co/documents/10179/19132/completo.pdf 
